\title{
Potential for Optimization in European Power Plant Fleet Operation
}

\author{
Bernhard-Johannes Jesse *(1), Simon Morgenthaler ${ }^{(\mathbb{D}}$, Bastian Gillessen ${ }^{(\mathbb{D}}$, Simon Burges and \\ Wilhelm Kuckshinrichs ${ }^{(D)}$ \\ Forschungszentrum Jülich, Institute of Energy and Climate Research-Systems Analysis and Technology \\ Evaluation (IEK-STE), D-52425 Jülich, Germany; s.morgenthaler@fz-juelich.de (S.M.); \\ ba.gillessen@fz-juelich.de (B.G.); s.burges@fz-juelich.de (S.B.); w.kuckshinrichs@fz-juelich.de (W.K.) \\ * Correspondence: b.jesse@fz-juelich.de; Tel.: +49-2461-61-3587
}

Received: 20 November 2019; Accepted: 3 February 2020; Published: 7 February 2020

\begin{abstract}
Energy policy makers need information about the greenhouse gas reduction potential that could be realized by changes to the operation of the currently existing European power plant fleet to enable short-term actions. Possible measures could reduce the climate impact of the European electricity system and, additionally, be realized quickly as new investments are avoided. In this paper, the Calliope based energy system model Stella of the European electricity system is presented and used for the first time, with the goal to quantify cost and $\mathrm{CO}_{2}$ emissions optimal operation strategies of the existing European power plant fleet. By applying the model to six scenarios the results show that the greenhouse gas emissions of the European power plant fleet could be reduced by more than $50 \%$ with little additional costs compared to today's power generation mix. It is shown that historic power plant operation follows only economic considerations while not fully covering its climate impact. The results demonstrate to policy makers the scale of reduction potential that could be achieved by short-term actions.
\end{abstract}

Keywords: greenhouse gas reduction; European power plant fleet; European electricity system; Calliope; Stella; energy system planning; emissions; power supply

\section{Introduction}

Identification and evaluation of climate change mitigation strategies is a key objective of energy systems analysis. As climate change progresses [1] and the pressure on energy policy makers to act rises, more and more resources are directed into the development and usage of corresponding energy system models in particular and the field of systems analysis in general [2]. Energy system models are applied to answer research questions that are not limited to the resilience of energy systems [3], the impact of changing heating and cooling demand due to climate change [4] or the altering potentials of electricity generation by renewable energies [5]. The following studies show applications of large-scale multi-regional energy system models in context of climate change mitigation strategies: Löffler et al. [6] use the global energy system model GENeSYS to model scenarios with special focus on coupling of electricity, transportation and heating sectors with a time frame up to the year 2050. The authors suggest a photovoltaic dominated renewable energy mix to achieve agreed global greenhouse gas reduction targets. Pursiheimo et al. [7] show similar results but further state the importance of power-to-x technologies in a future global energy system. Additionally, Fattori et al. [8] present an open local multi-regional energy system model in order to include citizens into the process of energy system planning. The purpose is to establish a crowd-source development. Examples for national energy system models and their usage in the context of climate change mitigation strategies are Tahir et al. [9] for China or Heinrichs et al. [10] for Germany. 
For reasons of quality, transparency, repetition and credibility, relevant energy system models are more and more modeled in open source modeling frameworks like Calliope [11], FINE [12], OSeMOSYS [13], PyPSA [14] or oemof [15]. The user models energy systems by paramerization and combination of predefined items. Model results are typically calculated by mathematical programming methods like continuous linear programming. An important issue is the establishment of required open databases. The openmod-initiative motivates modelers to create and provide such data [16].

Even though models and studies with focus on an optimal energy system design for future challenges exist, a study on the amount of carbon dioxide $\left(\mathrm{CO}_{2}\right)$ that could be saved within the existing energy system design by changing its operation is missing. Therefore, the goal of this study is the first quantitative estimation and discussion of a cost and $\mathrm{CO}_{2}$ emission optimal operation strategy of the existing European power plant fleet. As changes in operation strategy do not cause investments, improvements can be realized without significant cost increases. Therefore the energy system model Stella is used to analyze the cause-effect relationships between cost and emission optimal systems as well as model results and reality. Corresponding research questions are: What is the cost optimal operation strategy for the European power plant fleet neglecting existing market mechanisms e.g., ancillary services? What is the emission optimal strategy? How much $\mathrm{CO}_{2}$ emissions could be avoided and what are the corresponding costs? Which obstacles should be considered? This work is a debate contribution on how to mitigate climate change. An additional novelty of this work is the first application of the open-source modeling framework Calliope for modeling the European electricity system [11].

In literature adjacent studies have been published. Nevertheless, none answer the above mentioned research questions. Brown et al. [17] use a spatially and temporally resolved sector-coupled model of Europe (PyPSA-EUR-SEC-30) to assess the impact of either expanded cross-border transmission capacities or sector coupling in a $95 \%$ carbon dioxide reduction scenario. Gerbaulet et al. [18] develop decarbonization scenarios of the European electricity sector. Schlachtberger et al. [19] develop cost optimal scenarios of the European electricity system with special respect to weather data, cost parameters and policy constraints. A main result is that a $57 \% \mathrm{CO}_{2}$ reduction compared to the base year 1990 is also cost optimal.

In order to firstly examine the $\mathrm{CO}_{2}$ and cost reduction potential of the existing European power plant fleet by changing its operation strategy, the study is structured in the following way: The used energy system model together with its data is presented in Section 2. The considered scenarios are described in Section 3. Then, in Section 4, the results of the model runs are analyzed, and discussed in Section 5, followed by the conclusion in Section 6 .

\section{Methodology}

In this work the optimizing energy system model Stella is used to analyze the effects of different objective functions and constraints. The model created is based on Calliope [11]. The model was created using Calliope version 0.6.3 and solved using Gurobi version 8.1.1. Calliope is a Python based open source model framework. It is designed to model complex energy systems with a relatively simple configuration and setup. The user may decide between continuous and mixed integer linear programming. The mathematical formulation of all model equations and their implementation are described in detail in the documentation of Calliope, which can be found on www.callio.pe [20].

The model itself is a simplified representation of the European electricity system. It consists of 29 core regions and 11 outer regions. The core regions are the countries of the European Union as well as Norway and Switzerland excluding Malta and Cyprus. In addition, Denmark is divided into an eastern and a western region as they belong to different asynchronous control zones. Each of the core regions is represented by a node, has country-specific access to technologies and a country-specific demand for electricity. The outer regions consist of the following countries: Albania, Bosnia and Herzegovina, Cyprus, Montenegro, North Macedonia, Northern Ireland, Serbia, Ukraine as well as Morocco and Russia. These regions only have one technology available that acts as a source for 
electricity. They are represented as one node each. The individual nodes of the entire model are interconnected. For the net transfer capacities, values are interpolated from the 2010 statistical data [21] and the planned 2020 values from the TEN-YEAR NETWORK DEVELOPMENT PLAN 2016 [22]. The net transfer capacities describe the net capacity to transmit electricity between two regions in the model Figure 1 shows the regions covered in the model.

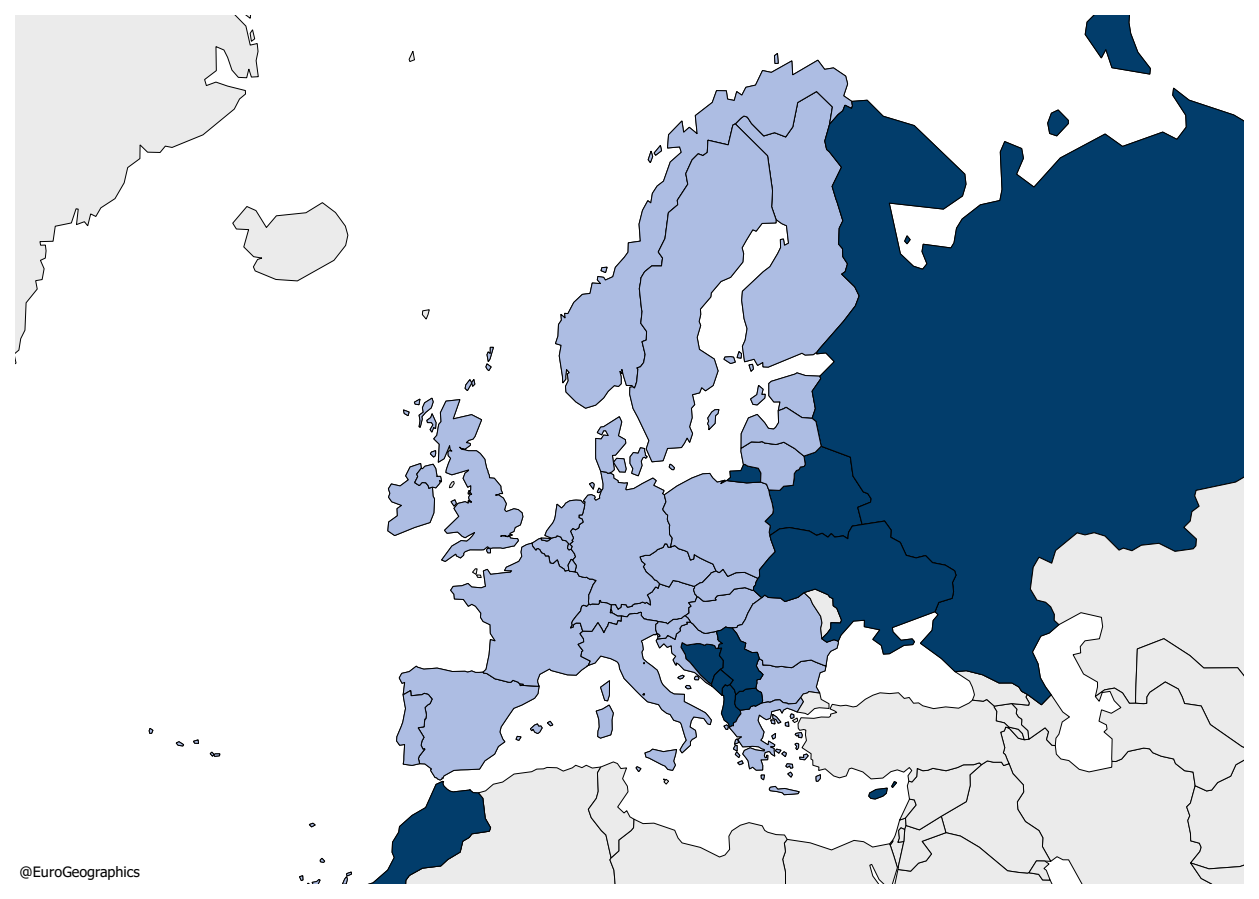

Figure 1. Map of the modeled regions, core (light blue) and outer (deep blue) regions.

On the map the core regions are coloured light blue whereas the outer regions are coloured deep blue. Countries not modeled are shown in grey.

In terms of technologies, a distinction is made between supply technologies and conversion technologies. Conversion technologies produce electricity by consuming a fuel. Supply technologies are sources for fuels, i.e., biomass, hard coal, lignite, natural gas, oil, uranium. For the outer regions no further technology distinction is applied however outer regions can supply electricity to the core regions for a fixed price. In the case of the power-generating conversion technologies, a distinction can be made between ten different fuel groups. The fuel groups and their respective technologies are listed in Table 1.

Table 1. Overview of fuel groups and technologies.

\begin{tabular}{cl}
\hline Fuel Group & \multicolumn{1}{c}{ Technologies } \\
\hline Solar & Photovoltaic system \\
Wind & Wind onshore, Wind offshore \\
Oil & Steam turbine \\
Gas & Open cycle gas turbine, Steam turbine, \\
& Combined cycle gas turbines \\
Hard coal & Steam turbine \\
Lignite & Steam turbine \\
Nuclear & Steam turbine \\
Biomass & Steam turbine \\
Hydro & Run-of-River, Reservoir storage \\
Other & Waste, Geothermal system, Other \\
\hline
\end{tabular}


A future expansion of the model to cover other sectors and energy carriers is easily feasible. Thus combined heat power plants are included as well as power-only plants. Even though the focus is on the electricity sector heat generation from combined heat and power plants is tracked. The model calculates both total system costs and total $\mathrm{CO}_{2}$ emissions. The model data are based on the data from [23]. Installed power plant capacities are generated using the powerplantmatching tool [24] that combines different power plant databases. The weather data used for photovoltaic and wind turbines are from www.renewables.ninja $[25,26]$, which provides bias corrected capacity factors. The $\mathrm{CO}_{2}$ emissions for the technologies in the model are mostly based on [27]. The electricity demand for the modelled regions are a model input and based on [28].

The group-share constraint of Calliope is applied to configure the power generation of specific fuel groups in individual countries in the model. This allows to set country-wise and fuel group-wise relative share of produced electricity. Using this constraint, the model can be adjusted in such a way that annual historical data is reproduced. However, this only applies with some limitations. For example, the hourly power plant deployment does not match historical data. In addition, not all fuel groups can be set in all countries, as otherwise the model will not compensate for statistical inconsistencies.

Both input and output data of the model have an hourly resolution, which allows a detailed analysis by time. In addition, the challenges arising from the fluctuation of wind and solar are better represented than with a coarser temporal resolution. Moreover, storage effects and effects on different time scales can be analyzed. An analysis of temporal resolution in energy system models and time series aggregation methods that could be applied in case of computational congestions are given in [29].

All model runs conducted for this paper were carried out on a workstation, with following specification: 16 CPU-Cores and 32 threads (Intel ${ }^{\circledR}$ Xeon ${ }^{\circledR}$ CPU E5-2667 v3 @ 3.2 GHz), 256 GB RAM (DDR4 @ $2113 \mathrm{MHz}$ ), Windows 8.1 Pro 64-bit.

\section{Scenarios}

For this analysis a total of six scenarios are developed to test the model and evaluate the ecological and economic potential of the current European power plant fleet. They include different optimization objectives and constraints. The optimization objectives are either minimizing the total system cost (all scenarios starting with Mon for monetary) or minimizing total $\mathrm{CO}_{2}$ emissions (all scenarios starting with Emi for emissions). The total system costs consist of the annualized investment, fixed operating costs and fuel costs. For both objectives constraints are introduced step wise. However, electricity demands and net transfer capacities for electricity are constant for all scenarios. In the Flex scenarios the composition of installed capacity is a model result and is left completely free. In contrast, in the Cap and CapShare scenarios, the capacities are model input. For the Cap scenarios the composition of the installed capacities are fixed to the statistical data of the existing European power plant fleet from 2015 (cf. Section 2). In these cases the composition of the installed capacities is no longer a model result but a model input. Thus, results show how the existing European power plant fleet can be operated in a cost-optimal or an emission-optimal manner to meet the power demand. Finally, the composition of the electricity production is fixed to the statistical data from 2015 in the CapShare scenarios. Due to data inconsistency a few constraints for the fixed production share had to be relaxed for the CapShare scenarios. Here, the model results will approximate the real total system costs and emissions as best as model inputs and constraints allow. Table 2 gives an overview of the modelled scenarios. 
Table 2. Overview of scenarios.

\begin{tabular}{ccccc}
\hline \multicolumn{2}{c}{ Name } & Objective & Capacity & Fixed Production Share \\
\hline \multirow{3}{*}{ Mon } & Flex & & variable & no \\
\cline { 4 - 5 } & Cap & Total system costs & fixed & hydro and other only \\
\cline { 4 - 5 } & CapShare & & 2015 & yes \\
\hline \multirow{2}{*}{ Emi } & Flex & & variable & no \\
\cline { 4 - 5 } & Cap & $\mathrm{CO}_{2}$ emission & fixed & hydro and other only \\
\cline { 3 - 4 } & CapShare & & 2015 & yes \\
\hline
\end{tabular}

Note: ${ }^{1}$ As all capacities are an exogenous model input for the Cap scenarios the overall investments cost are fixed and thus have no impact on the optimization process.

The CapShare scenarios are intended to validate the model and serve as a references for the other scenarios. The MonCap and EmiCap scenarios are used to evaluate, respectively, the economic and the ecological potential of the existing European power plant fleet. The Flex scenarios are best-case scenarios.

\section{Results}

The model results are analyzed by a set of performance indicators comprising installed capacities, load factors, total system costs and emissions as well as the share of electricity produced by the fuel group. To validate the model, the results of the CapShare scenarios are compared with historical data from [30]. This data stem officially from ENTSO-E, the European Network of Transmission System Operators, which is the best source available for such data. Figure 2 shows the deviation of the load factors of the fuel groups in the different regions.

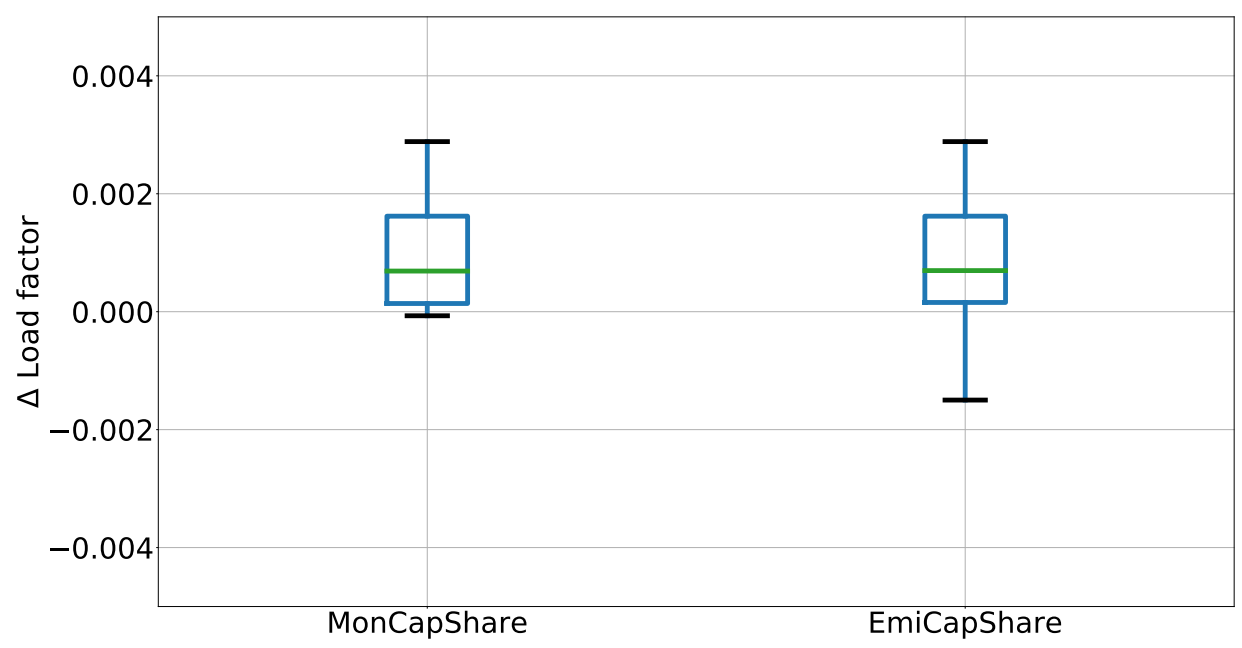

Figure 2. Deviation between CapShare scenarios and real world data for the load factor.

The representation as a box plot allows the statistical distribution of the deviation to be examined. The deviation of the load factors are between 0.002 and 0.0 for the two scenarios. Outliers are not shown but can be found in Appendix A (Figure A1). In addition to the validation with the load factors, the generated electricity was also used for validation. Again, most deviations are in a very small range. The corresponding figures can be found in Appendix A (Figures A2 and A3). The reason for the discrepancy is twofold. Firstly, data inconsistencies in the statistical data. Secondly, the model optimizes operation on the basis of annualized total system costs, whereas power plant operators often decide operation based on marginal costs. However, in total, the deviations for both parameters are very small. As the deviations for both scenarios are very small they can serve as a reference. 
The time resolution chosen allows a detailed analysis of the calculated electricity production. Figure 3 a shows the temporal profile of electricity production over all core regions for the MonCapShare scenario. A partial section for the week from 01 June 2015 to 07 June 2015 is given in Figure 3b to enable a more detailed look.

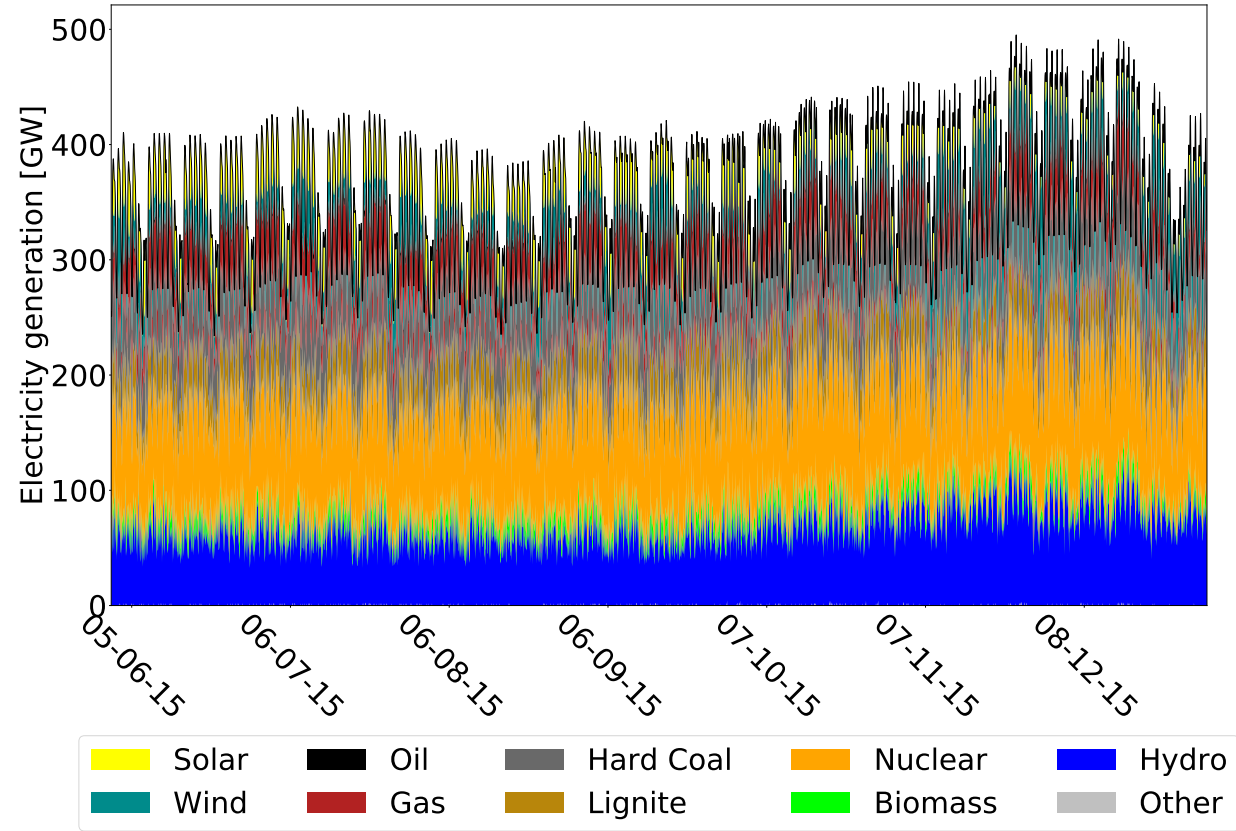

(a) European electricity generation by fuel group in 2015 (MonCapShare)

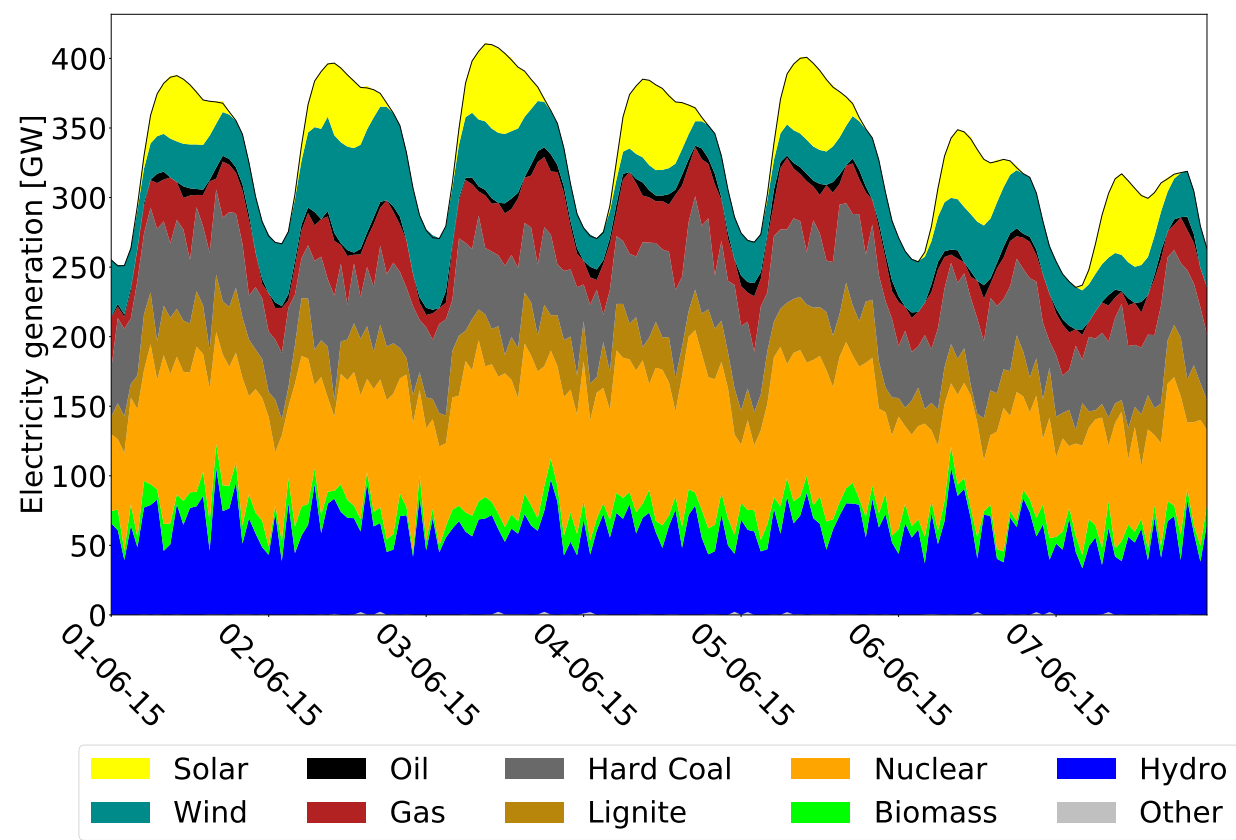

(b) European electricity generation by fuel group in the first week of June in 2015 (MonCapShare).

Figure 3. European electricity generation by fuel group.

The temporal course of power generation and demand reveal numerous insights. Firstly, the demand varies on several time scales. It is represented by the top black line and is the sum of the individual demand curves of the countries. Figure 3a shows the seasonal fluctuation and in Figure $3 \mathrm{~b}$ the differences between weekdays and weekends can be seen. Nevertheless, the typical 
daily demand curve appears. Secondly, electricity generation from wind and solar vary from different time scales. Finally, the electricity generation by fuel group is influenced by the electricity generation of the other fuel groups. For example, when solar and wind generate a particularly large amount of electricity, conventional power plants produce less electricity.

Figure 4 shows the total installed capacity for all scenarios. These are summed up for the core regions and sorted by fuel group.

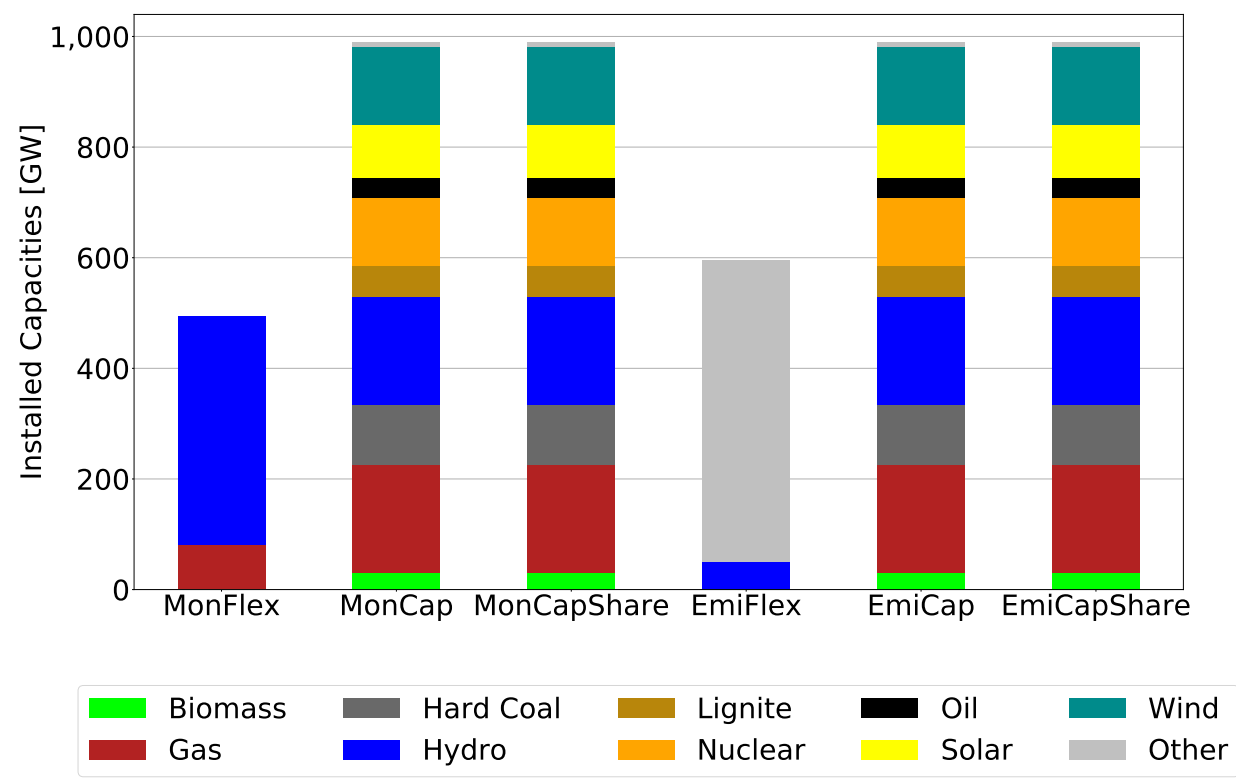

Figure 4. Comparison of installed capacity by fuel group and scenario.

The installed capacity in the two Flex scenarios is only about $49.8 \%$ and $60.0 \%$ of the 2015 capacity values from the other scenarios. In addition, it can be seen that hydro power plants are choosen to a great extent in the MonFlex scenario due to their favourable costs and the unlimited hydro power potential in the scenario. The composition of the installed capacity in the EmiFlex scenario, which is a model result, needs further discussion. In the EmiFlex scenario, the objective of model optimization is the minimization of $\mathrm{CO}_{2}$ emissions. While the emissions in the EmiFlex scenario are zero, there is a wide range of possible solutions using different technologies leading to power demand fulfillment without emissions. Since only total emissions and not total system costs are minimized, the model can randomly choose from all technologies with zero $\mathrm{CO}_{2}$ emissions. This can be seen in the results for installed capacities, which shows that only capacities of the fuel groups hydro and other are used (Figure 4). In the four Cap scenarios the installed capacities are fixed (model input) and thus the same.

Besides the installed capacities, the contribution of the individual fuel groups to the total electricity production and the extent to which the installed capacities are utilized are examined. These two parameters are shown in Figure 5a. The utilization is presented in Figure $5 \mathrm{~b}$ as a load factor. This factor results from the ratio of the actually produced amount of electricity and the theoretically maximum possible produced amount of electricity. 


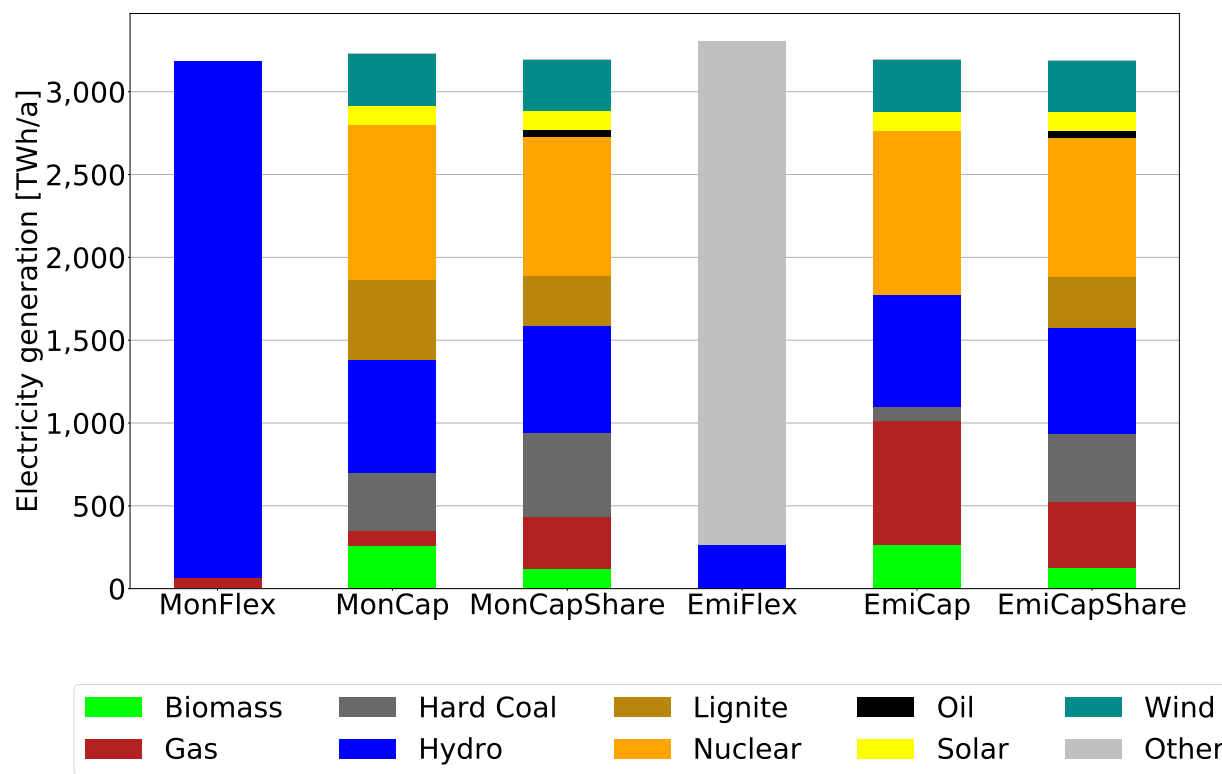

(a) Electricity generation by fuel group and scenario

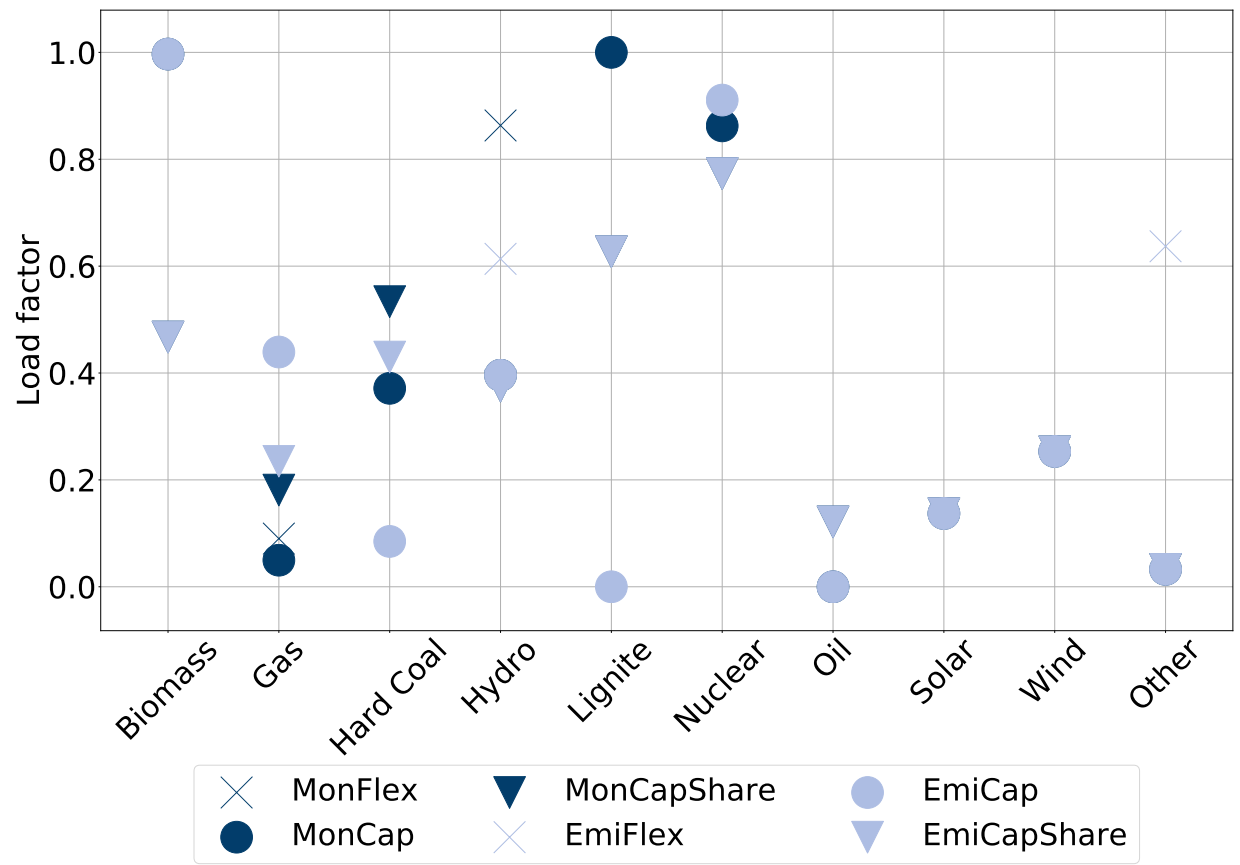

(b) Average load factors of aggregated fuel groups by scenario

Figure 5. Comparison of electricity generation by fuel group and their average load factor per scenario.

The total amount of generated electricity differs slightly between the six scenarios. However, imported electricity from outer regions is not shown in Figure 5a. The EmiFlex scenario has the highest amount of produced electricity with $3306.9 \mathrm{TWh} / \mathrm{a}$. The scenario with the lowest amount of electricity is the MonFlex scenario with an electricity production of $3183.7 \mathrm{TWh} / \mathrm{a}$. This equals a difference of 3.7\%. The scenarios MonCapShare, EmiCap and EmiCapShare have almost identical values (3197.3 TWh/a, 3197.6 TWh/a and 3191.1 TWh/a). The value for the MonCap scenario is also close, with $3234.1 \mathrm{TWh} / \mathrm{a}$. For electricity generation in the Flex scenarios, it can be seen that electricity is generated in accordance to the installed capacities. In these scenarios, electricity generation is limited to two fuel groups. The results in terms of power generation for the MonCap and EmiCap scenarios 
are very similar. For example, the amount of electricity from hydro, wind and solar are identical as capacity factors on the one hand and production share constraints on the other hand are set for these fuel groups in these scenarios. Other fuel groups, such as nuclear and biomass, have a similar share in the two Cap scenarios. Differences exist primarily in electricity production based on hard coal, lignite and gas. In the MonCap scenario, more hard coal and lignite is used to generate electricity, while in the EmiCap scenario more electricity is generated using gas. For the two scenarios MonCapShare and EmiCapShare, the allocation of the produced electricity is almost identical as expected. Both the fuel groups used and their respective share in electricity production show almost no differences between the results of MonCapShare and EmiCapShare. The deviations are limited due to the above mentioned constraints fixing the electricity production share. For both CapShare scenarios a similar situation in the utilization of the fuel groups is revealed. The load factors for all scenarios and the respective fuel groups are shown in Figure 5b. Load factors only exist for fuel groups with installed capacities. In case capacities are installed but not used, the load factor is zero.

The load factor for biomass is at maximum for both MonCap and EmiCap scenarios, which means that the installed capacities have 8760 full load hours per year. In the MonFlex and EmiFlex scenarios there are no capacities for biomass, which results in no load factors. For the scenarios with production share constraints, the load factors for biomass are identical with $46.7 \%$. The load factors for gas differ significantly between the scenarios. First of all, it can be seen that there is no load factor for the EmiFlex scenario because there is no capacity for gas. The factor for the MonFlex scenario is relatively low, while at the same time the installed capacity for gas in this scenario is low. The load factor of gas is relatively similar for the MonCapShare and the EmiCapShare scenarios at $18.1 \%$ and $23.5 \%$ respectively (Figure 5b). Differences are caused by the minimal solution space. The load factor for gas of the MonCap and EmiCap scenario is lower. For example, the load factor of gas in the MonCap scenario is very low at $9.0 \%$. In contrast, the EmiCap calculation has the highest load factor compared to all other scenarios with a value of over $40.0 \%$. For hard coal, the results show that the values for the two scenarios MonCapShare and EmiCapShare are again relatively close (53.3\% and 43.0\%). The load factors for the MonCap and the EmiCap scenario distinguish for hard coal. The load factor of hard coal with $37.1 \%$ for the MonCap is much higher than the $8.4 \%$ for the EmiCap scenario. The load factors for hydro power in the MonFlex have the highest value with $86.3 \%$, while in the EmiFlex it has a load factor of $61.4 \%$. The load of hydro in both Cap calculations is lower with $39.6 \%$, whereby the values for EmiCap and MonCap are almost identical. Exactly the same are the load factors of hydro for the CapShare scenarios. At $37.5 \%$, these values are slightly lower compared to the values of the EmiCap and MonCap scenarios.

The biggest difference in load factors can be seen for lignite. The load factor in the MonCap scenario is $100.0 \%$, while in the EmiCap scenario it is $0.0 \%$. The load factors for EmiCapShare and MonCapShare are again identical at a value of $62.7 \%$. MonFlex and EmiFlex have no capacities for both lignite and nuclear and, hence, no load factors. The load factor of nuclear capacity is the same for the MonCapShare and EmiCapShare calculations with $77.3 \%$. The load factor for MonCap is $86.3 \%$ and for EmiCap is only slightly higher with $91.5 \%$. The difference between these two is relatively small. For the fuel group oil, the installed capacities in the EmiCap and MonCap scenarios are not used, which results in load factor of $0.0 \%$. The load factors in the MonCapShare and in the EmiCapShare is the same and low with $12.1 \%$. For solar and wind the load factors of the four Cap scenarios MonCap, MonCapShare, EmiCap and EmiCapShare are the same with $13.7 \%$ and $25.3 \%$. Due to a lack of installed capacity, there are no load factors for the two Flex scenarios. Only the fuel group other has installed capacities in the EmiFlex scenario. It has a relatively high load factor with $63.7 \%$. In the MonFlex scenario there is no capacity for other and therefore no load factor exists. In the remaining four scenarios, the load factors of other installed capacity is nearly equal with $3.3 \%$.

For the Mon scenarios, the total system costs are the objective to be minimized. As stated before, in the MonCap and MonCapShare scenarios the investment costs are fixed based on model inputs and therefore have no influence on the optimization. All scenarios can be examined on their resulting 
total system costs. The resulting costs for all scenarios can be seen in Figure $6 \mathrm{~b}$, whereby a distinction is made between investment costs, operation costs and fuel costs. In the MonFlex scenario, the total system costs are notably low.

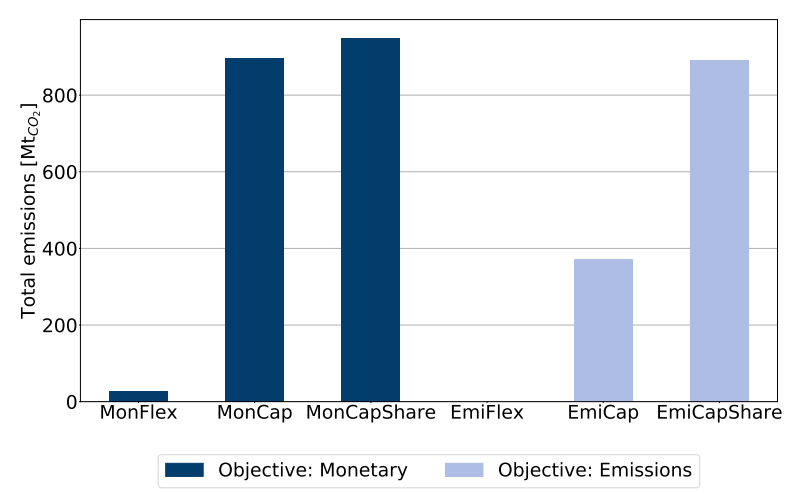

(a) Carbon dioxide emissions by scenario

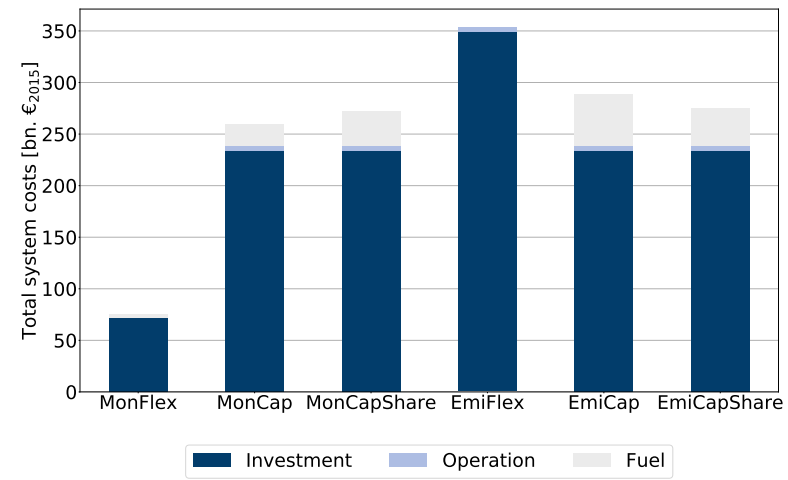

(b) Cost comparison by scenario split into investment costs, operation costs and costs for fuels

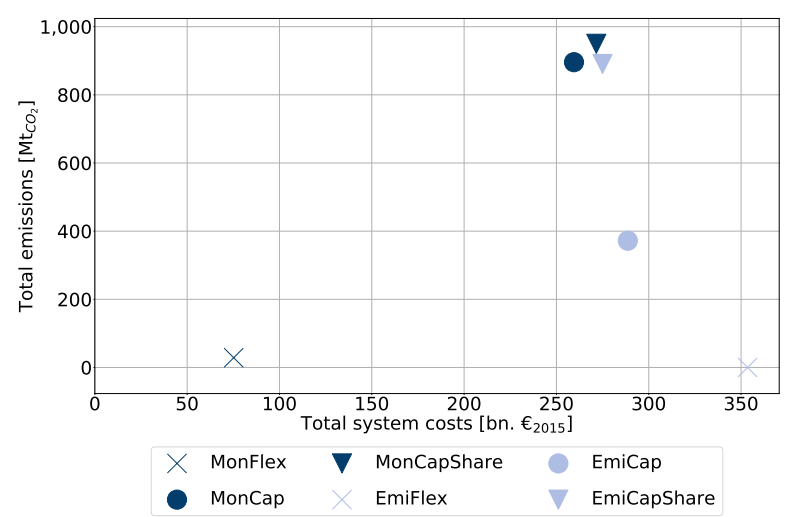

(c) Total $\mathrm{CO}_{2}$ emissions over total system costs

Figure 6. Comparison of annualized total system costs and total emissions.

In contrast the highest total system costs arise for the EmiFlex scenario. There are no fuel costs in this scenario. However, because the objective of this scenario is total $\mathrm{CO}_{2}$ emissions and it is not optimized according to total system costs, the costs resulting here are not necessarily the cost-optimal solution due to the installed capacities. For the remaining four scenarios, the investment costs of $234 \mathrm{bn}$. $€$ and the operation cost of $4.21 \mathrm{bn}$. $€$ are always the same, as these depend on the installed capacities. The total system costs for these scenarios therefore only differ according to the fuel costs. 
The total system costs of MonCapShare and EmiCapShare are almost identical and differ only by a difference of $3.4 \mathrm{bn}$. $€$ per year.

In addition to monetary costs, $\mathrm{CO}_{2}$ emissions are another indicator that is important for the evaluation. The $\mathrm{CO}_{2}$ quantities emitted in the individual scenarios are shown in Figure 6a. As expected, $\mathrm{CO}_{2}$ emissions are lowest in the scenarios with minimum number of constraints. The amount of $\mathrm{CO}_{2}$ emitted in the MonFlex scenario is $28.6 \mathrm{Mt}_{\mathrm{CO}_{2}}$. The EmiFlex calculation, in which the objective is the minimization of $\mathrm{CO}_{2}$ emissions, shows that there is at least one option to achieve zero $\mathrm{CO}_{2}$ emissions. The highest emitted quantities of $\mathrm{CO}_{2}$ can be found in the MonCapShare calculation. In this scenario the amount of $\mathrm{CO}_{2}$ is $949.7 \mathrm{Mt}_{\mathrm{CO}_{2}}$. Emissions in EmiCapShare are slightly lower at $890.6 \mathrm{Mt}_{\mathrm{CO}_{2}}$. The solver uses its solution space to minimize $\mathrm{CO}_{2}$ emissions. The emissions in the MonCap scenario are $895.8 \mathrm{Mt}_{\mathrm{CO}_{2}}$. In comparison, the emissions for the EmiCap scenario are only $371.9 \mathrm{Mt}_{\mathrm{CO}_{2}}$. The emissions of the MonCap calculation are, thus, almost 2.5 times higher. Figure $6 \mathrm{c}$ shows the results for total system costs and total $\mathrm{CO}_{2}$ emissions for the individual runs. Especially noticeable is the large difference in total system costs $(278.3 \mathrm{bn}$. $€$ ) while differences in emissions $\left(28.6 \mathrm{Mt}_{\mathrm{CO}_{2}}\right.$ ) are small between the MonFlex and the EmiFlex calculation. However, it should be noted that the EmiFlex calculation does not necessarily choose the most cost effective solution to achieve zero emissions. The results of the MonCap and EmiCap scenarios is worth emphasizing. Here, the difference between total system costs is small (29.2 bn. $€$ ), while the difference between $\mathrm{CO}_{2}$ emissions is large (523.9 $\mathrm{Mt}_{\mathrm{CO}_{2}}$ ) indicating a big potential for improvements. Next, the difference between the MonCap and the MonCapShare calculation is small, but the MonCapShare calculation costs slightly more (12.1 bn. $€$ ) and has more $\mathrm{CO}_{2}$ emissions (53.9 $\mathrm{Mt}_{\mathrm{CO}_{2}}$ ). The difference between the EmiCap and the EmiCapShare scenario is greater. The cost in the EmiCap calculation is slightly higher (13.7 bn. $€$ ), but the amount of $\mathrm{CO}_{2}$ emitted is less than half the amount in the EmiCapShare scenario (890.6 $\mathrm{Mt}_{\mathrm{CO}_{2}}$ in EmiCapShare and $371.9 \mathrm{Mt}_{\mathrm{CO}_{2}}$ in EmiCap). It is particularly interesting that the result of the MonCap calculation does not differ too much from the results of the CapShare scenarios for both, total system costs and total emissions.

In addition to considering total system costs at the European level, the levelized cost of electricity (LCoE) can also be examined at the country level. The levelized costs are calculated by dividing the annualized total costs per country by the total amount of produced electricity per country

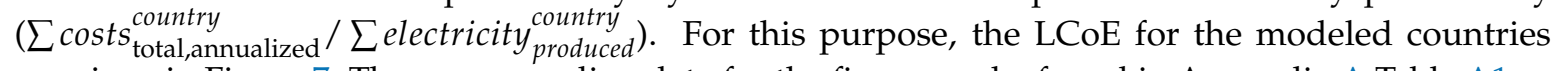
are given in Figure 7. The corresponding data for the figure can be found in Appendix A Table A1.

The LCoE range between 2.6 and 20.0 Cent/ kWh in the four scenarios MonCap, MonCapShare, EmiCap and EmiCapShare for most countries. Only in a few exceptions the LCoE are above 20.0 Cent/kWh, like Luxembourg in the EmiCap scenario. Norway has low LCoE in all four scenarios with 2.6-2.7 Cent/kWh. In contrast, Lithuania has high LCoE in all scenarios with values of 31.1-33.5 Cent $/ \mathrm{kWh}$. The high LCoE for the Baltic States are noticeable. When the MonCapShare scenario is compared with the EmiCapShare scenario, only a minor difference can be observed. Compared to the MonCapShare scenario, the LCoEs in the MonCap scenario change in Germany, Denmark, Belgium, Greece and Estonia. On the one hand, in Denmark, Belgium and Greece the LCoE in the MonCap scenario are higher than in the MonCapShare scenario. On the other hand, for Germany and Estonia the value in the MonCap scenario is lower, from $10.5 \mathrm{Cent} / \mathrm{kWh}$ to $9.8 \mathrm{Cent} / \mathrm{kWh}$ and from 17.3 Cent $/ \mathrm{kWh}$ to $12.7 \mathrm{Cent} / \mathrm{kWh}$. The LCoE in Estonia fall by $4.6 \mathrm{Cent} / \mathrm{kWh}$ between the EmiCap and the EmiCapShare scenario. Other countries whose LCoEs differ between the EmiCap and the EmiCapShare scenario are Germany, Denmark, Greece, Luxembourg and Portugal. The LCoE in Denmark and Luxembourg are increasing. In Luxembourg the increase is quite high with an increase from 11.1 Cent $/ \mathrm{kWh}$ in the EmiCap scenario to $49.0 \mathrm{Cent} / \mathrm{kWh}$. In Germany, Greece and Portugal, the LCoE drop. In comparison, the LCoE in Sweden, Norway and Finland are robust and differ only slightly between the individual scenarios. An overview of the amount of electricity produced for each country can be found in the Appendix A (Tables A2-A5). 


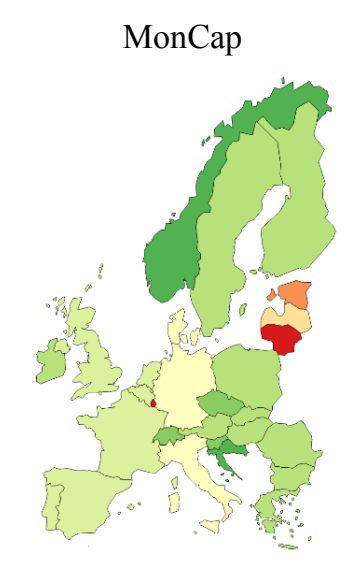

EmiCap

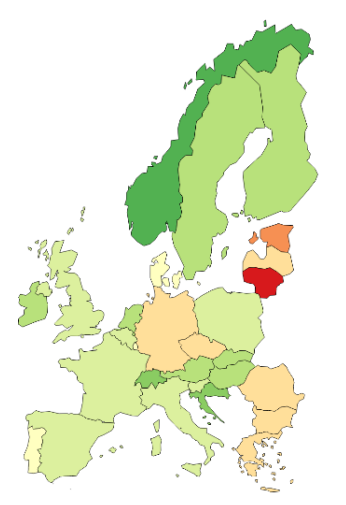

MonCapShare

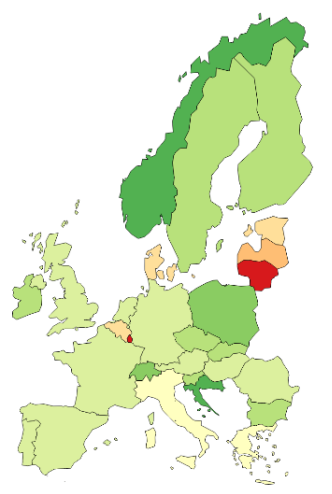

EmiCapShare

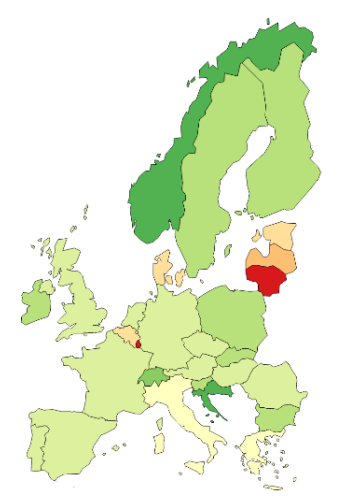

$0-2$

$2-4$

$4-6$

$6-8$

$8-10$

$10-12$

$12-14$ อ

$14-16$

$16-18$

$18-20$

$>20$

Figure 7. Levelized cost of electricity for the modeled region for given scenarios.

\section{Discussion}

The scenario analysis allows a variety of insights. This section discusses what explanations might be given for the nature of the results regarding installed capacities and generated electricity. The significance of the cost and emission results of the individual scenarios will also be examined. Finally, it is explored what influences the levelized cost of electricity and why different regions are affected differently.

The solution of the MonFlex calculation shows a high installed capacity for hydro because of its low costs. Furthermore, hydro is being used with a high load factor of $86.3 \%$. In comparison, the load factor in the calibrated CapShare scenarios is less than half at $37.5 \%$. Therefore, it has to be noted that the high amount of electricity generated by hydro in the MonFlex scenario is not reasonable under real world circumstances. The amount of water available for electricity generation is in the real world limited by external factors, e.g., melt-water. When interpreting the results for the EmiFlex scenario, the statements from Section 4 should be kept in mind. The objective for this calculation is the minimization of $\mathrm{CO}_{2}$ emissions. Because several technologies exist that do not emit $\mathrm{CO}_{2}$, there is a wide solution space. The solution found here is only one of many and is most likely not the cost-optimal. The installed capacities in the remaining scenarios are the same due to the fact that these are given to the model as input as they represent the European power plant fleet from 2015 (cf. Section 2).

The results show a difference in the absolute amount of electricity generated, while the absolute electricity demand stays constant, because it is a model input. The amounts of produced electricity differ in fact between the scenarios due to the different use of storage technologies, like pumpstorages. 
Since these technologies have an efficiency of less than one, electricity is lost during charging and discharging. To compensate for this, more electricity has to be produced than if the electricity would have not be stored.

The following findings can be derived from the results for electricity generation and the utilization of the European power plant fleet. In the MonFlex calculation, for example, hydro power plants are the main source of electricity because they are associated with low levelized cost of electricity (LCoE) while natural constraints (e.g., water availability, feasibility of installations) are neglected. Gas is used, in addition to hydro, in this scenario. Gas is chosen as a second technology to fill the gap between demand and generation by hydro, because it has low investment costs compared to the other technologies (cf. Appendix A Table A6). Electricity production and load factors in the MonCapShare and EmiCapShare scenarios are almost identical. The remaining differences for electricity production can be explained by the remaining solution space. Since the capacities are specified in the two CapShare scenarios, the marginal production costs are pivotal for the selection of technologies needed to meet the electricity demand. Depending on the objective function, the cheapest technologies available are selected in the MonCapShare calculation and the technologies with lowest specific $\mathrm{CO}_{2}$ emissions are selected in the EmiCapShare calculation. Thus, in the MonCapShare scenario the load factor of hard coal is $10.4 \%$ higher (53.4\% instead of $43.0 \%$ ) but that of gas $5.4 \%$ lower $(18.1 \%$ instead of $23.5 \%$ ) than in the EmiCapShare scenario. In the MonCap scenario technologies with low fuel costs such as lignite, nuclear and biomass are used to their full capacity. Technologies with high fuel costs such as gas and hard coal are used less in comparison to the CapShare calculations. Oil is not used for electricity production. For the EmiCap calculation, the technologies are used according to their specific $\mathrm{CO}_{2}$ emissions. Biomass and nuclear have particularly high load factors of $99.7 \%$ and $91.1 \%$, respectively. Local bottlenecks and fully utilized interconnector capacities prevent a load factor of $100 \%$. For fossil fuel based technologies, gas makes the largest contribution to electricity generation. Of the remaining fossil fuel technologies, only hard coal contributes to electricity generation, accounting for $2.5 \%$ of total electricity production. Oil and lignite are not used at all due to their high specific $\mathrm{CO}_{2}$ emissions. The difference in load factors for hydro between the Cap and the CapShare scenarios can be explained by the fact that hydro does not have a production share constraint for all countries.

The results of the MonCapShare and EmiCapShare calcuations are closest to real world data due to the input data and constraints of the model and deviate only slightly from the statistic values (cf. Section 4). While the total system costs and total emissions of the MonCap scenario are similar to those of the CapShare scenarios, there are some differences. One factor for the difference to the statistical data are technical restrictions that are not implemented in the model. Furthermore, all capacities in the model are primarily used for electricity generation. Plants which in reality are heat-operated or driven by industrial demand are modeled as electricity-operated. While some technologies in the model produce heat as well, their primary task is to cover the electricity demand. In reality, however, industrial power plants exist that cover a demand for process heat and their electricity generation is only of secondary interest. Another factor for the deviations is that no electricity market mechanisms, such as balancing power, are reflected in the model.

The comparison of total system costs and total $\mathrm{CO}_{2}$ emissions show that for the MonFlex scenario the annualized total system costs are as low as expected, while the $\mathrm{CO}_{2}$ emissions for this scenario are low, although the objective is total system costs. However, this result is purely academic in nature, as the calculated capacity and quantity of electricity produced by hydro is not reasonable. The reason why the values of total system costs and total emissions are not identical for the two CapShare calculations is, as already described above, due to the remaining solution space of the optimization. The fact that the results of the MonCap scenario are close to the ones of the MonCapShare scenario shows that there is little optimization potential in terms of total system costs. This is mainly due to the high share of investment costs in total system costs, which are only dependent on the installed capacities and are model inputs. That is why it is more informative to examine the fuel costs. The potential saving by a different operation of the existing European power plant fleet in fuel costs for the MonCap scenario 
are $36.3 \%$ compared to the ones in the MonCapShare scenario. It should be noted that technical limitations and market mechanisms, e.g., ramping constraints and minimum power, are neglected in the model. Therefore the real savings potential is lower. The similar comparison between the EmiCap and the EmiCapShare scenario shows that there is a large savings potential for $\mathrm{CO}_{2}$ emissions.

The results clearly show, that there is a great potential to reduce the total $\mathrm{CO}_{2}$ emissions of power generation with the existing European power plant fleet at comparable low additional total system costs. The total system costs of the EmiCap scenario is higher than those of the EmiCapShare scenario, but only by $5.0 \%$. The fuel costs are about $37.2 \%$ higher in the EmiCap scenario than in the EmiCapShare scenario. The savings potential of total $\mathrm{CO}_{2}$ emissions is therefore not only high, there are also only minor additional total system costs.

However, this result has different effects on the levelized cost of electricity (LCoE) in the modeled countries. The changes in the LCoE are mainly due to two effects. The first effect is the different utilization of technologies between scenarios due to the underlying objective function and constraints. Thus in the MonCap scenario expensive electricity from technologies such as gas and oil is replaced by less expensive electricity from technologies such as hard coal, biomass or hydro. Contrary, the capacity utilization in the EmiCap scenario is determined by the specific $\mathrm{CO}_{2}$ emissions of the different technologies. Therefore, more technologies with low specific $\mathrm{CO}_{2}$ emissions such as biomass, gas, hydro or nuclear are used instead of technologies such as hard coal, lignite and oil. However, this may lead to a higher utilization of technologies that are more expensive. The second effect, why the LCoE differ in the scenarios, is the electricity production in the respective countries. In some countries, like Bulgaria, the amount of electricity produced in the MonCap scenario is smaller than in the MonCapShare scenario. In other countries it is the other way round. The reason why the quantities of electricity produced in countries differ between the individual scenarios is due to the combination of the composition of the respective power plants, the objective function and the capacities of the interconnectors. The interaction of cost of technologies and generated electricity on the LCoE is not always straightforward, as the dominating driver may vary from one country to another. For example, in Germany more gas and oil are used in the MonCapShare scenario and less hard coal, lignite, biomass and hydro than in the MonCap scenario. In addition, electricity production in Germany is higher in the MonCapShare scenario with $532.9 \mathrm{TWh} / \mathrm{a}$ than in the MonCap scenario with $481.2 \mathrm{TWh} / \mathrm{a}$. As a result, the LCoE for Germany in the MonCapShare scenario with 9.8 Cent $/ \mathrm{kWh}$ are lower than in the MonCap scenario where the LCoE for Germany is $10.5 \mathrm{Cent} / \mathrm{kWh}$. The effect of utilizing more expensive technologies in Germany is therefore smaller than the effect of increased electricity production. For regions like Denmark West exactly the opposite is the case. Here the additional electricity production is too low to cancel out the effect of the more expensive technologies chosen, which is why the LCoE are higher in the MonCapShare scenario than in the MonCap scenario. The impact of the two effects on the LCoE is particularly evident for the LCoE of Luxembourg for the comparision of the EmiCap and EmiCapShare scenarios. Here the expensive and emission-rich technology oil is used more in the EmiCapShare scenario than in the EmiCap scenario. Contrary, in the EmiCap scenario more biomass, gas and hydro is used than in the EmiCapShare scenario. At the same time, the amount of electricity produced in the EmiCap scenario (4.2 TWh/a) is 5.7 times higher than in the EmiCapShare scenario (0.7 TWh/a). Overall, this leads to a decrease of the LCoE for Luxembourg from 49.0 Cent $/ \mathrm{kWh}$ in the EmiCapShare scenario to $11.1 \mathrm{Cent} / \mathrm{kWh}$ in the EmiCap scenario. This can be explained by the fact that instead of expensive technology less expensive technologies are used while the amount of electricity produced increases.

The extent to which the LCoE differ between the scenarios depends on the use of the technologies and the amount of electricity produced in the countries. The focus on technologies with low specific $\mathrm{CO}_{2}$ emissions in the EmiCap scenario, for example, does cause additional total system costs. However, not all countries are affected to the same extent. As expected, the LCoE increase in some countries compared to the LCoE in the EmiCapShare scenario. However, there are also countries like Belgium, 
Italy or Luxembourg in which the LCoE as well as the $\mathrm{CO}_{2}$ emissions decrease between the two scenarios. These countries profit twice from an optimization in regards to $\mathrm{CO}_{2}$ emissions.

\section{Conclusions}

Climate change causes energy policy makers in Europe and around the world to think about measures to decrease green house gas emissions. The European power plant fleet contributes significantly to the greenhouse gas emissions in Europe and, hence, is a possible object for reduction activities. Energy policy makers and energy system analysts need an estimation for the reduction potential that could be realized with the existing European power plant fleet and what are related costs.

In this study the model of the European electricity system Stella is introduced. The implementation is carried out in Calliope, an open-source modeling framework programmed in Python. The model covers 29 European regions, which are represented in 29 interconnected nodes. A given time series of electricity demand is covered by thermal or renewable generation technologies during the solution process. Objective function is minimization of either annualized total system costs or $\mathrm{CO}_{2}$ emissions. To achieve the goal of this study, six scenarios have been developed. Two scenarios cover the electricity demand for 2015 in an unconstrained way minimizing either total system costs or total emissions. In four additional scenarios the European power plant capacities are imprinted on the model, which means that investment costs have no impact on the optimization. In two of these four scenarios historical production values are fixed enabling a comparison of historical and potential values.

The scenario results show that the greenhouse gas emissions of the European power plant fleet could be reduced potentially by more than $50 \%$ with low additional total system costs of around $5 \%$ resulting in relative low specific $\mathrm{CO}_{2}$ abatement costs. The results further show that today's operation strategy of the European power plant fleet is close to a cost optimal manner. Hence, the results prove the economic manner of today's power plant operation with only little consideration of its corresponding climate influence.

The results motivate further research in how to establish incentives for energy suppliers to generate more electricity from climate friendly electricity sources. For investigation, the constraints of heat-operated power plants in the industrial and public power plants could be examined and included in the model. To set up the model a lot of input data is required. Data is often specified with a bandwidth. However, exact values are required as model inputs. In a future study this issue can be addressed by performing a sensitivity analysis, which shows the influence of different parameters on the results. Finally, the results could be checked for robustness, for example by using solar and wind data from multiple years.

Author Contributions: Conceptualization, B.-J.J., S.M., B.G. and S.B.; Data curation, B.-J.J., S.M., B.G. and S.B.; Investigation, B.-J.J., S.M., B.G. and S.B.; Methodology, B.-J.J., S.M., B.G. and S.B.; Software, B.-J.J., S.M., B.G. and S.B.; Supervision, W.K.; Validation, B.-J.J., S.M., B.G. and S.B.; Visualization, B.-J.J., S.M., B.G. and S.B.; Writing一original draft, B.-J.J., S.M., B.G. and S.B.; Writing-review \& editing, B.-J.J., S.M., B.G., S.B. and W.K. All authors have read and agree to the published version of the manuscript.

Funding: This research received no external funding.

Conflicts of Interest: The authors declare no conflict of interest. 


\section{Appendix A}

Table A1. Levelized cost of electricity by scenario and country [Cent $2015 / \mathrm{kWh}]$.

\begin{tabular}{|c|c|c|c|c|}
\hline & MonCap & MonCapShare & EmiCap & EmiCapShare \\
\hline Austria (AT) & 7.7 & 9.6 & 6.4 & 9.0 \\
\hline Belgium (BE) & 9.6 & 13.8 & 8.7 & 13.1 \\
\hline Bulgaria (BG) & 7.3 & 6.4 & 12.7 & 8.0 \\
\hline Switzerland $(\mathrm{CH})$ & 4.3 & 4.5 & 4.1 & 4.5 \\
\hline Czechia (CZ) & 5.9 & 7.8 & 13.0 & 9.1 \\
\hline Germany (DE) & 10.5 & 9.8 & 12.7 & 9.7 \\
\hline Denmark-East (DKE) & 11.5 & 12.0 & 12.6 & 11.9 \\
\hline Denmark-West (DKW) & 11.5 & 13.2 & 10.6 & 13.1 \\
\hline Estonia (EE) & 17.3 & 12.7 & 17.3 & 12.7 \\
\hline Spain (ES) & 8.7 & 9.7 & 9.4 & 9.4 \\
\hline Finland (FI) & 6.2 & 7.0 & 6.7 & 6.9 \\
\hline France (FR) & 8.4 & 9.7 & 8.2 & 9.7 \\
\hline Great Britain (GB) & 8.5 & 9.0 & 8.9 & 8.6 \\
\hline Greece (GR) & 7.3 & 10.3 & 12.1 & 10.1 \\
\hline Croatia (HR) & 4.0 & 3.9 & 4.0 & 3.9 \\
\hline Hungary (HU) & 7.2 & 8.8 & 7.4 & 8.2 \\
\hline Ireland (IE) & 6.5 & 7.0 & 8.0 & 7.0 \\
\hline Italy (IT) & 10.3 & 10.6 & 9.8 & 10.1 \\
\hline Lithuania (LT) & 34.1 & 33.5 & 31.1 & 33.5 \\
\hline Luxembourg (LU) & 46.6 & 57.3 & 11.1 & 49.0 \\
\hline Latvia (LV) & 12.4 & 15.6 & 12.4 & 15.6 \\
\hline Netherlands (NL) & 9.7 & 8.5 & 7.9 & 8.0 \\
\hline Norway (NO) & 2.6 & 2.7 & 2.6 & 2.7 \\
\hline Poland (PL) & 6.3 & 5.3 & 8.3 & 7.4 \\
\hline Portugal (PT) & 8.3 & 8.7 & 10.9 & 8.9 \\
\hline Romania (RO) & 6.6 & 8.7 & 12.2 & 8.7 \\
\hline Sweden (SE) & 7.4 & 7.3 & 7.4 & 7.3 \\
\hline Slovenia (SI) & 5.4 & 7.4 & 8.2 & 7.4 \\
\hline Slovakia (SK) & 6.2 & 6.7 & 6.5 & 6.7 \\
\hline
\end{tabular}

Table A2. Electricity generation [TWh/a]-MonCap.

\begin{tabular}{lrrrrrrrrrr}
\hline & Biomass & Gas & Hard Coal & Hydro & Lignite & Nuclear & Oil & Other & Solar & Wind \\
\hline AT & 10.4 & 0.0 & 0.7 & 38.5 & 0.0 & 0.0 & 0.0 & 0.1 & 1.2 & 5.7 \\
BE & 7.2 & 1.1 & 2.1 & 1.7 & 0.0 & 51.1 & 0.0 & 0.0 & 3.5 & 5.4 \\
BG & 0.5 & 0.0 & 0.0 & 5.7 & 32.1 & 4.2 & 0.0 & 0.0 & 1.4 & 1.4 \\
CH & 2.7 & 0.0 & 0.0 & 112.5 & 0.0 & 23.7 & 0.0 & 0.0 & 2.3 & 0.1 \\
CZ & 6.6 & 0.0 & 0.2 & 2.3 & 73.3 & 21.9 & 0.0 & 0.0 & 2.5 & 0.6 \\
DE & 63.1 & 0.0 & 17.7 & 19.6 & 163.2 & 89.1 & 0.0 & 0.3 & 43.9 & 84.3 \\
DKE & 4.7 & 0.0 & 1.2 & 0.0 & 0.0 & 0.0 & 0.0 & 0.0 & 0.3 & 4.4 \\
DKW & 4.7 & 0.0 & 0.4 & 0.0 & 0.0 & 0.0 & 0.0 & 0.0 & 0.5 & 9.5 \\
EE & 1.5 & 0.0 & 0.0 & 0.0 & 0.0 & 0.0 & 0.0 & 0.0 & 0.0 & 0.7 \\
ES & 7.9 & 3.9 & 57.4 & 31.6 & 26.4 & 66.3 & 0.0 & 0.0 & 7.2 & 50.4 \\
FI & 16.7 & 0.0 & 14.4 & 16.6 & 0.0 & 24.3 & 0.0 & 0.1 & 0.0 & 3.1 \\
FR & 7.0 & 0.0 & 0.4 & 55.2 & 0.0 & 510.3 & 0.0 & 0.0 & 8.4 & 22.5 \\
\hline
\end{tabular}


Table A2. Cont.

\begin{tabular}{lrrrrrrrrrr}
\hline & Biomass & Gas & Hard Coal & Hydro & Lignite & Nuclear & Oil & Other & Solar & Wind \\
\hline GB & 37.7 & 16.6 & 105.6 & 9.7 & 0.0 & 78.1 & 0.0 & 0.0 & 8.8 & 43.9 \\
GR & 0.4 & 0.1 & 0.0 & 1.5 & 39.9 & 0.0 & 0.0 & 0.0 & 3.7 & 4.9 \\
HR & 0.5 & 0.0 & 0.0 & 15.2 & 0.0 & 0.0 & 0.0 & 0.0 & 0.1 & 0.5 \\
HU & 4.3 & 0.0 & 0.1 & 0.2 & 8.8 & 15.3 & 0.0 & 0.0 & 0.2 & 0.7 \\
IE & 0.5 & 5.5 & 8.0 & 1.2 & 2.2 & 0.0 & 0.0 & 0.0 & 0.0 & 6.8 \\
IT & 25.9 & 51.8 & 74.9 & 44.3 & 0.0 & 0.0 & 0.0 & 0.9 & 25.7 & 13.8 \\
LT & 0.6 & 0.0 & 0.0 & 0.3 & 0.0 & 0.0 & 0.0 & 0.0 & 0.1 & 1.1 \\
LU & 0.1 & 0.0 & 0.0 & 0.3 & 0.0 & 0.0 & 0.0 & 0.0 & 0.1 & 0.1 \\
LV & 1.1 & 0.0 & 0.0 & 1.9 & 0.0 & 0.0 & 0.0 & 0.0 & 0.0 & 0.2 \\
NL & 4.7 & 4.0 & 31.3 & 0.1 & 0.0 & 4.3 & 0.0 & 0.9 & 1.7 & 8.0 \\
NO & 0.0 & 0.0 & 0.0 & 201.9 & 0.0 & 0.0 & 0.0 & 0.0 & 0.0 & 2.2 \\
PL & 8.4 & 0.0 & 23.7 & 2.7 & 82.9 & 0.0 & 0.0 & 0.0 & 0.1 & 11.1 \\
PT & 4.7 & 2.1 & 15.3 & 9.5 & 0.0 & 0.0 & 0.0 & 0.0 & 0.7 & 11.1 \\
RO & 1.0 & 0.0 & 0.0 & 16.5 & 41.0 & 4.1 & 0.0 & 0.0 & 1.6 & 6.5 \\
SE & 37.5 & 0.0 & 0.0 & 74.0 & 0.0 & 23.8 & 0.0 & 0.0 & 0.1 & 15.5 \\
SI & 0.5 & 0.0 & 0.0 & 3.9 & 8.3 & 6.3 & 0.0 & 0.0 & 0.3 & 0.0 \\
SK & 2.1 & 0.0 & 0.0 & 12.9 & 4.3 & 15.7 & 0.0 & 0.0 & 0.6 & 0.0 \\
\hline
\end{tabular}

Table A3. Electricity generation [TWh/a]-MonCapShare.

\begin{tabular}{lrrrrrrrrrr}
\hline & Biomass & Gas & Hard Coal & Hydro & Lignite & Nuclear & Oil & Other & Solar & Wind \\
\hline AT & 3.3 & 0.6 & 3.8 & 32.5 & 0.0 & 0.0 & 1.1 & 0.1 & 1.2 & 5.7 \\
BE & 3.0 & 7.6 & 4.1 & 0.3 & 0.0 & 26.1 & 0.2 & 0.0 & 3.5 & 5.4 \\
BG & 0.2 & 1.3 & 14.0 & 5.7 & 18.7 & 14.3 & 0.0 & 0.0 & 1.4 & 1.4 \\
CH & 0.1 & 0.1 & 0.0 & 110.4 & 0.0 & 22.9 & 0.0 & 0.0 & 2.3 & 0.1 \\
CZ & 2.0 & 5.0 & 15.4 & 1.8 & 33.4 & 25.8 & 0.0 & 0.0 & 2.5 & 0.6 \\
DE & 39.3 & 0.4 & 110.5 & 16.1 & 145.0 & 87.9 & 5.6 & 0.3 & 43.7 & 84.1 \\
DKE & 0.4 & 0.0 & 5.5 & 0.0 & 0.0 & 0.0 & 0.0 & 0.0 & 0.3 & 4.4 \\
DKW & 1.9 & 0.1 & 1.3 & 0.0 & 0.0 & 0.0 & 0.1 & 0.0 & 0.5 & 9.5 \\
EE & 1.3 & 0.0 & 0.0 & 0.0 & 0.0 & 0.0 & 5.9 & 0.0 & 0.0 & 0.7 \\
ES & 4.6 & 39.1 & 48.6 & 27.5 & 4.5 & 54.8 & 13.0 & 0.0 & 7.2 & 50.3 \\
FI & 11.1 & 9.6 & 6.3 & 16.6 & 0.0 & 22.9 & 0.5 & 0.1 & 0.0 & 3.1 \\
FR & 7.0 & 0.8 & 8.6 & 53.7 & 0.0 & 416.1 & 3.4 & 0.0 & 8.4 & 22.5 \\
GB & 0.1 & 87.4 & 95.0 & 4.7 & 0.0 & 65.7 & 0.0 & 0.0 & 8.8 & 43.7 \\
GR & 0.2 & 8.9 & 0.0 & 0.7 & 19.8 & 0.0 & 0.1 & 0.0 & 3.7 & 4.9 \\
HR & 0.0 & 0.8 & 2.1 & 15.0 & 0.0 & 0.0 & 0.0 & 0.0 & 0.1 & 0.5 \\
HU & 1.6 & 0.1 & 0.5 & 0.2 & 5.6 & 15.0 & 0.0 & 0.0 & 0.2 & 0.7 \\
IE & 0.0 & 8.5 & 4.9 & 1.1 & 2.2 & 0.0 & 0.1 & 0.0 & 0.0 & 6.8 \\
IT & 20.1 & 92.7 & 42.3 & 43.2 & 0.0 & 0.0 & 6.4 & 0.9 & 25.7 & 13.7 \\
LT & 0.4 & 0.2 & 0.0 & 0.3 & 0.0 & 0.0 & 0.0 & 0.0 & 0.1 & 1.1 \\
LU & 0.1 & 0.1 & 0.0 & 0.1 & 0.0 & 0.0 & 0.0 & 0.0 & 0.1 & 0.1 \\
LV & 0.4 & 0.0 & 0.0 & 1.9 & 0.0 & 0.0 & 0.0 & 0.0 & 0.0 & 0.2 \\
NL & 4.7 & 29.8 & 21.5 & 0.1 & 0.0 & 4.3 & 0.1 & 0.9 & 1.6 & 8.0 \\
NO & 0.0 & 3.5 & 0.0 & 195.6 & 0.0 & 0.0 & 0.0 & 0.0 & 0.0 & 2.2 \\
PL & 7.0 & 4.5 & 106.0 & 1.8 & 52.1 & 0.0 & 0.2 & 0.0 & 0.1 & 11.1 \\
PT & 2.6 & 5.4 & 13.7 & 8.5 & 0.0 & 0.0 & 0.1 & 0.0 & 0.7 & 11.0 \\
RO & 0.5 & 0.0 & 2.1 & 16.5 & 15.7 & 11.0 & 0.3 & 0.0 & 1.6 & 6.5 \\
SE & 10.0 & 1.1 & 0.5 & 74.4 & 0.0 & 54.8 & 0.0 & 0.0 & 0.1 & 15.5 \\
SI & 0.2 & 0.0 & 0.0 & 3.8 & 3.9 & 5.5 & 0.0 & 0.0 & 0.3 & 0.0 \\
SK & 1.1 & 1.9 & 1.0 & 12.7 & 1.7 & 14.4 & 0.0 & 0.0 & 0.6 & 0.0 \\
\hline & & & & & & & & & 0.0 \\
\hline
\end{tabular}


Table A4. Electricity generation [TWh/a]—EmiCap.

\begin{tabular}{lrrrrrrrrrr}
\hline & Biomass & Gas & Hard Coal & Hydro & Lignite & Nuclear & Oil & Other & Solar & Wind \\
\hline AT & 10.4 & 32.7 & 0.0 & 37.2 & 0.0 & 0.0 & 0.0 & 0.1 & 1.2 & 5.7 \\
BE & 7.2 & 16.8 & 0.0 & 1.2 & 0.0 & 51.3 & 0.0 & 0.0 & 3.5 & 5.4 \\
BG & 0.5 & 0.2 & 0.0 & 5.7 & 0.0 & 17.1 & 0.0 & 0.0 & 1.4 & 1.4 \\
CH & 2.7 & 0.0 & 0.0 & 117.5 & 0.0 & 25.6 & 0.0 & 0.0 & 2.3 & 0.1 \\
CZ & 6.6 & 2.6 & 0.0 & 2.4 & 0.0 & 33.9 & 0.0 & 0.0 & 2.5 & 0.6 \\
DE & 63.1 & 119.0 & 0.1 & 20.5 & 0.0 & 94.6 & 0.0 & 0.3 & 43.9 & 84.3 \\
DKE & 4.7 & 0.3 & 0.0 & 0.0 & 0.0 & 0.0 & 0.0 & 0.0 & 0.3 & 4.4 \\
DKW & 4.7 & 2.7 & 0.0 & 0.0 & 0.0 & 0.0 & 0.0 & 0.0 & 0.5 & 9.5 \\
EE & 1.5 & 0.0 & 0.0 & 0.0 & 0.0 & 0.0 & 0.0 & 0.0 & 0.0 & 0.7 \\
ES & 7.9 & 98.1 & 0.0 & 27.7 & 0.0 & 66.3 & 0.0 & 0.0 & 7.2 & 50.4 \\
FI & 16.7 & 12.2 & 0.0 & 16.6 & 0.0 & 24.3 & 0.0 & 0.1 & 0.0 & 3.1 \\
FR & 7.0 & 0.5 & 0.0 & 62.2 & 0.0 & 519.8 & 0.0 & 0.0 & 8.4 & 22.5 \\
GB & 37.7 & 141.9 & 0.0 & 5.3 & 0.0 & 78.1 & 0.0 & 0.0 & 8.8 & 43.9 \\
GR & 0.4 & 28.9 & 0.0 & 0.7 & 0.0 & 0.0 & 0.0 & 0.0 & 3.7 & 4.9 \\
HR & 0.5 & 0.7 & 0.0 & 15.1 & 0.0 & 0.0 & 0.0 & 0.0 & 0.1 & 0.5 \\
HU & 4.3 & 12.7 & 0.0 & 0.2 & 0.0 & 16.6 & 0.0 & 0.0 & 0.2 & 0.7 \\
IE & 0.5 & 14.4 & 0.0 & 1.0 & 0.0 & 0.0 & 0.0 & 0.0 & 0.0 & 6.8 \\
IT & 25.9 & 166.4 & 0.0 & 43.9 & 0.0 & 0.0 & 0.0 & 0.9 & 25.7 & 13.8 \\
LT & 0.6 & 0.2 & 0.0 & 0.3 & 0.0 & 0.0 & 0.0 & 0.0 & 0.1 & 1.1 \\
LU & 0.1 & 3.2 & 0.0 & 0.6 & 0.0 & 0.0 & 0.0 & 0.0 & 0.1 & 0.1 \\
LV & 1.1 & 0.0 & 0.0 & 1.9 & 0.0 & 0.0 & 0.0 & 0.0 & 0.0 & 0.2 \\
NL & 4.7 & 74.2 & 0.0 & 0.1 & 0.0 & 4.3 & 0.0 & 0.9 & 1.7 & 8.0 \\
NO & 0.0 & 0.0 & 0.0 & 201.9 & 0.0 & 0.0 & 0.0 & 0.0 & 0.0 & 2.2 \\
PL & 8.4 & 11.4 & 80.7 & 1.8 & 0.0 & 0.0 & 0.0 & 0.0 & 0.1 & 11.1 \\
PT & 4.7 & 7.0 & 0.0 & 8.5 & 0.0 & 0.0 & 0.0 & 0.0 & 0.7 & 11.1 \\
RO & 1.0 & 0.1 & 0.0 & 16.5 & 0.0 & 11.7 & 0.0 & 0.0 & 1.6 & 6.5 \\
SE & 37.5 & 0.0 & 0.0 & 74.1 & 0.0 & 24.0 & 0.0 & 0.0 & 0.1 & 15.5 \\
SI & 0.5 & 2.7 & 0.0 & 3.8 & 0.0 & 6.4 & 0.0 & 0.0 & 0.3 & 0.0 \\
SK & 2.1 & 2.5 & 0.0 & 13.0 & 0.0 & 17.0 & 0.0 & 0.0 & 0.6 & 0.0 \\
\hline & & & & & & & & & 0.0 \\
\hline
\end{tabular}

Table A5. Electricity generation [TWh/a]—EmiCapShare.

\begin{tabular}{lrrrrrrrrrr}
\hline & Biomass & Gas & Hard Coal & Hydro & Lignite & Nuclear & Oil & Other & Solar & Wind \\
\hline AT & 3.3 & 6.6 & 3.8 & 32.5 & 0.0 & 0.0 & 1.1 & 0.1 & 1.2 & 5.7 \\
BE & 3.0 & 11.0 & 4.1 & 0.3 & 0.0 & 26.1 & 0.2 & 0.0 & 3.5 & 5.4 \\
BG & 0.2 & 1.3 & 0.0 & 5.7 & 18.7 & 14.3 & 0.0 & 0.0 & 1.4 & 1.4 \\
CH & 0.1 & 0.1 & 0.0 & 110.4 & 0.0 & 22.9 & 0.0 & 0.0 & 2.3 & 0.1 \\
CZ & 2.0 & 5.0 & 0.0 & 1.8 & 33.4 & 25.8 & 0.0 & 0.0 & 2.5 & 0.6 \\
DE & 39.3 & 13.0 & 110.5 & 16.1 & 145.0 & 87.9 & 5.6 & 0.3 & 43.7 & 84.1 \\
DKE & 0.5 & 0.0 & 5.6 & 0.0 & 0.0 & 0.0 & 0.0 & 0.0 & 0.3 & 4.4 \\
DKW & 1.8 & 0.4 & 1.3 & 0.0 & 0.0 & 0.0 & 0.1 & 0.0 & 0.5 & 9.5 \\
EE & 1.3 & 0.0 & 0.0 & 0.0 & 0.0 & 0.0 & 5.9 & 0.0 & 0.0 & 0.7 \\
ES & 4.6 & 52.7 & 48.6 & 27.5 & 4.5 & 54.8 & 13.0 & 0.0 & 7.2 & 50.3 \\
FI & 11.1 & 12.2 & 6.3 & 16.6 & 0.0 & 22.9 & 0.5 & 0.1 & 0.0 & 3.1 \\
FR & 7.0 & 4.3 & 8.6 & 53.7 & 0.0 & 416.1 & 3.4 & 0.0 & 8.4 & 22.5 \\
GB & 0.1 & 107.7 & 95.0 & 4.7 & 0.0 & 65.7 & 0.0 & 0.0 & 8.8 & 43.7 \\
GR & 0.2 & 10.0 & 0.0 & 0.7 & 19.8 & 0.0 & 0.1 & 0.0 & 3.7 & 4.9 \\
HR & 0.0 & 0.8 & 2.1 & 15.0 & 0.0 & 0.0 & 0.0 & 0.0 & 0.1 & 0.5 \\
HU & 1.6 & 3.1 & 0.5 & 0.2 & 5.6 & 15.0 & 0.0 & 0.0 & 0.2 & 0.7 \\
IE & 0.0 & 8.1 & 4.9 & 1.1 & 2.2 & 0.0 & 0.1 & 0.0 & 0.0 & 6.8 \\
IT & 20.1 & 113.0 & 42.3 & 43.2 & 0.0 & 0.0 & 6.4 & 0.9 & 25.7 & 13.7 \\
LT & 0.4 & 0.2 & 0.0 & 0.3 & 0.0 & 0.0 & 0.0 & 0.0 & 0.1 & 1.1 \\
LU & 0.1 & 0.3 & 0.0 & 0.1 & 0.0 & 0.0 & 0.0 & 0.0 & 0.1 & 0.1 \\
LV & 0.4 & 0.0 & 0.0 & 1.9 & 0.0 & 0.0 & 0.0 & 0.0 & 0.0 & 0.2 \\
NL & 4.7 & 37.4 & 21.5 & 0.1 & 0.0 & 4.3 & 0.1 & 0.9 & 1.6 & 8.0 \\
NO & 0.0 & 3.5 & 0.0 & 195.6 & 0.0 & 0.0 & 0.0 & 0.0 & 0.0 & 2.2 \\
\hline
\end{tabular}


Table A5. Cont.

\begin{tabular}{lrrrrrrrrrr}
\hline & Biomass & Gas & Hard Coal & Hydro & Lignite & Nuclear & Oil & Other & Solar & Wind \\
\hline PL & 7.0 & 4.5 & 36.7 & 1.8 & 52.1 & 0.0 & 0.2 & 0.0 & 0.1 & 11.1 \\
PT & 2.6 & 4.0 & 13.7 & 8.5 & 0.0 & 0.0 & 0.1 & 0.0 & 0.7 & 11.0 \\
RO & 0.5 & 0.0 & 2.1 & 16.5 & 15.7 & 11.0 & 0.3 & 0.0 & 1.6 & 6.5 \\
SE & 10.0 & 1.1 & 0.5 & 74.4 & 0.0 & 54.8 & 0.0 & 0.0 & 0.1 & 15.5 \\
SI & 0.2 & 0.0 & 0.0 & 3.8 & 3.9 & 5.5 & 0.0 & 0.0 & 0.3 & 0.0 \\
SK & 1.1 & 1.9 & 1.0 & 12.7 & 1.7 & 14.4 & 0.0 & 0.0 & 0.6 & 0.0 \\
\hline
\end{tabular}

Table A6. Techno-economic parameters which are used as model input data for all scenarios.

\begin{tabular}{|c|c|c|c|c|c|}
\hline & Fuel Group & $\begin{array}{r}\text { Investment Cost } \\
{\left[€_{2015} / \mathbf{k W}\right]}\end{array}$ & $\begin{array}{l}\text { O\&M Cost } \\
{\left[€_{2015} / \mathrm{kW}\right]}\end{array}$ & $\begin{array}{r}\text { Lifetime } \\
{[\mathrm{a}]}\end{array}$ & $\begin{array}{r}\text { Efficiency } \\
{[\%]}\end{array}$ \\
\hline ConELC-PP_COA & Hard Coal & 1365 & 27 & 45 & 35 \\
\hline ConELC-PP_LIG & Lignite & 1552 & 33 & 45 & 35 \\
\hline ConELC-PP_NG-OCGT & Gas & 568 & 17 & 40 & 45 \\
\hline ConELC-PP_NG-ST & Gas & 750 & 19 & 40 & 30 \\
\hline ConELC-PP_NG-CCGT & Gas & 855 & 26 & 40 & 60 \\
\hline ConELC-PP_OIL & Oil & 750 & 20 & 40 & 25 \\
\hline ConELC-PP_NUC & Nuclear & 5000 & 43 & 50 & 33 \\
\hline ConELC-PP_BIO & Biomass & 2306 & 92 & 25 & 28 \\
\hline ConELC-PP_HYD-ROR & Hydro & 1454 & 15 & 200 & - \\
\hline ConELC-PP_HYD-STO & Hydro & 1385 & 28 & 200 & - \\
\hline ConELC-PP_HYD-PST & Hydro & 1385 & 28 & 200 & 86.6 \\
\hline ConELC-PP_WON & Wind & 1400 & 34 & 25 & - \\
\hline ConELC-PP_WOF & Wind & 3000 & 106 & 25 & - \\
\hline ConELC-PP_SPV & Solar & 3378 & 51 & 25 & - \\
\hline ConELC-PP_CSP & Solar & 5200 & 104 & 25 & - \\
\hline ConELC-PP_GEO & Other & 2400 & 84 & 30 & - \\
\hline ConELC-PP_WST & Other & 2530 & 51 & 30 & - \\
\hline ConELC-PP_OTH & Other & 5500 & 55 & 20 & - \\
\hline ConELC-CHP_COA & Hard Coal & 1646 & 33 & 45 & 40 \\
\hline ConELC-CHP_LIG & Lignite & 1872 & 40 & 45 & 30 \\
\hline ConELC-CHP_NG-OCGT & Gas & 568 & 17 & 40 & 40 \\
\hline ConELC-CHP_NG-ST & Gas & 1182 & 21 & 40 & 31 \\
\hline ConELC-CHP_NG-CCGT & Gas & 823 & 21 & 40 & 40 \\
\hline ConELC-CHP_OIL & Oil & 1182 & 20 & 40 & 10 \\
\hline ConELC-CHP_BIO & Biomass & 2306 & 0 & 25 & 40 \\
\hline ConELC-CHP_GEO & Other & 2400 & 84 & 25 & - \\
\hline ConELC-CHP_WST & Other & 2530 & 51 & 30 & - \\
\hline ConELC-CHP_OTH & Other & 5500 & 55 & 20 & - \\
\hline
\end{tabular}

Table A7. Cost and emission data for fuels which are used as model input data for all scenarios.

\begin{tabular}{lrr}
\hline & $\begin{array}{r}\text { Cost } \\
{\left[€_{\mathbf{2 0 1 5}} / \mathbf{k W h}_{\mathbf{f u e l}}\right]}\end{array}$ & $\begin{array}{r}\text { Emissions } \\
{\left[\mathbf{k g}_{\mathrm{CO}_{\mathbf{2}}} / \mathbf{k W h}_{\text {fuel }}\right]}\end{array}$ \\
\hline Biomass Supply & 0.001 & 0 \\
Crude Oil Supply & 0.0260 & 0.2786 \\
Electricity Supply (outer regions) & 0.3 & 0.5 \\
Hard Coal Supply & 0.0061 & 0.3406 \\
Lignite Supply & 0.0013 & 0.3643 \\
Natural Gas Supply & 0.0207 & 0.2020 \\
Uranium Supply & 0.0033 & 0.0050 \\
\hline
\end{tabular}




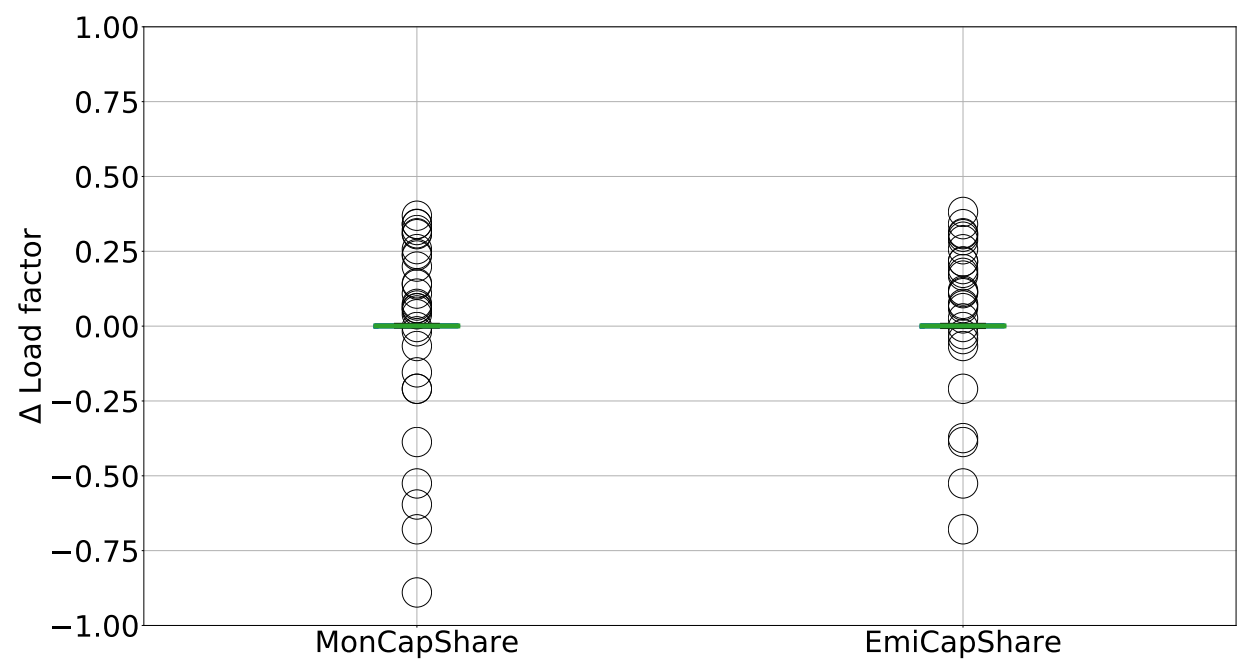

Figure A1. Deviation between CapShare scenarios and real world data for the load factor with outliers.

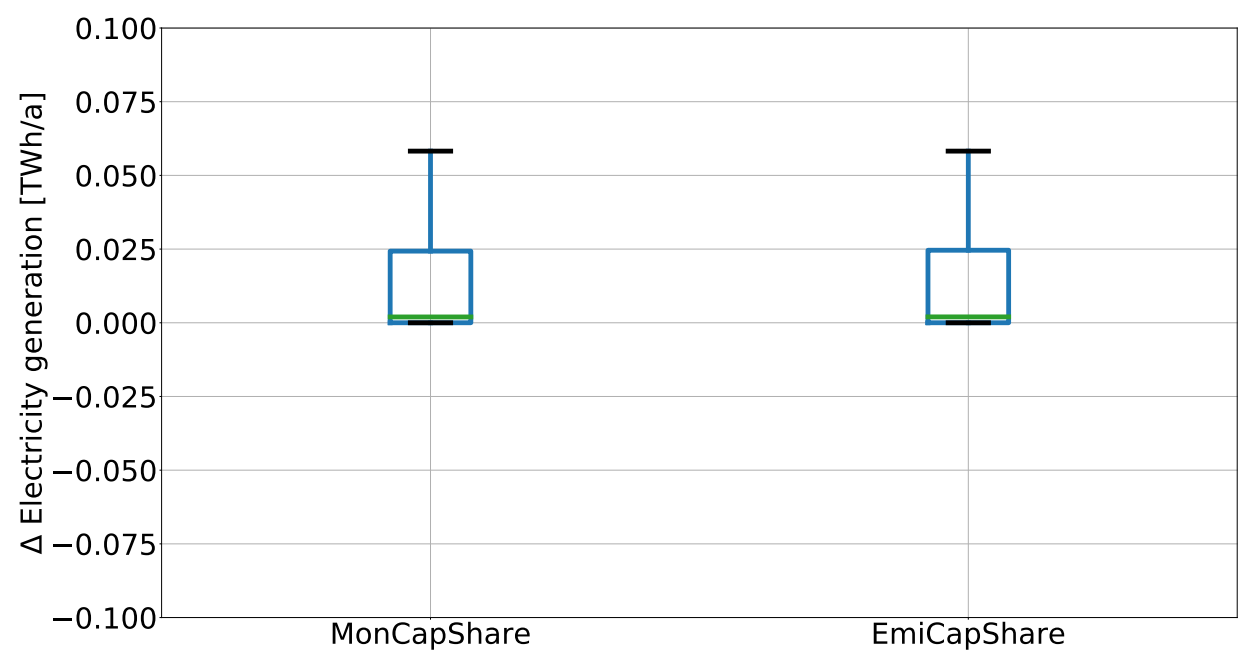

Figure A2. Deviation between CapShare scenarios and real world data for the generated electricity.

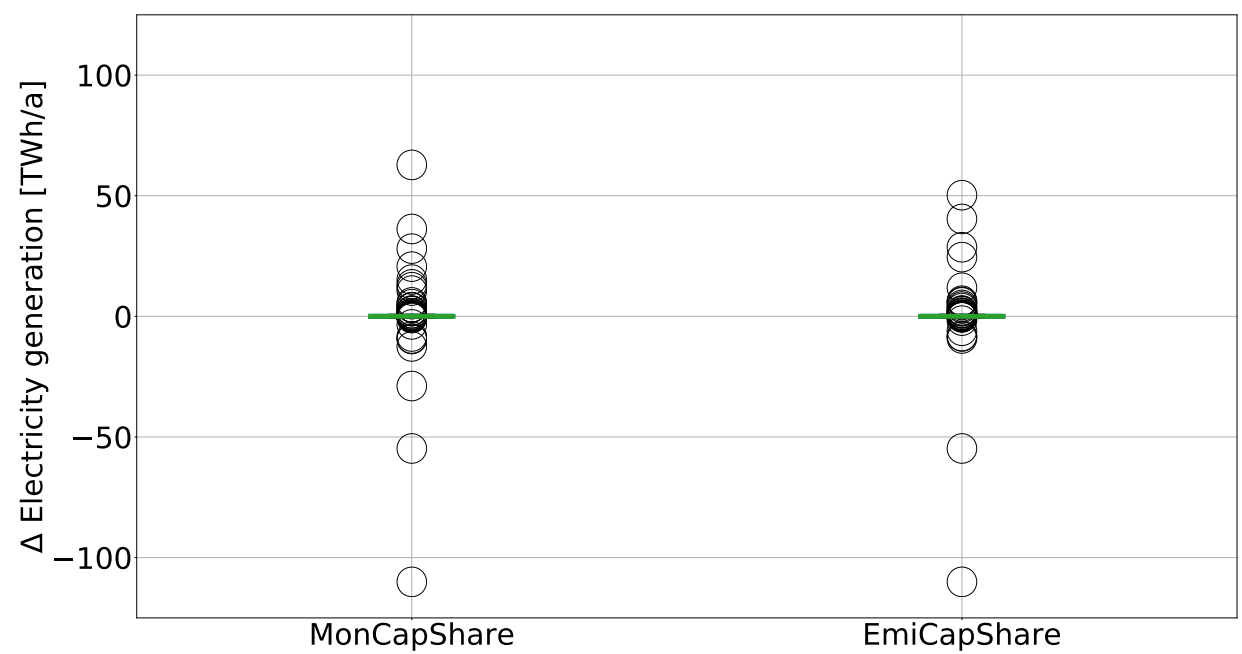

Figure A3. Deviation between CapShare scenarios and real world data for the generated electricity with outliers. 


\section{References}

1. Intergovernmental Panel on Climate Change (IPCC). Summary for Policymakers. In Global Warming of $1.5^{\circ} \mathrm{C}$. An IPCC Special Report on the Impacts of Global Warming of $1.5^{\circ} \mathrm{C}$ above Pre-Industrial Levels and Related Global Greenhouse Gas Emission Pathways, in the Context of Strengthening the Global Response to the Threat of Climate Change, Sustainable Development, and Efforts to Eradicate Poverty; IPCC: Geneva, Switzerland, 2018.

2. Federal Ministry for Economic Affairs and Energy (BMWi). Innovation durch Forschung_Erneuerbare Energien und Energieeffizienz: Projekte und Ergebnisse der Forschungsförderung 2018; Federal Ministry for Economic Affairs and Energy (BMWi): Berlin, Germany, 2019.

3. European Environment Agency (EEA). Adaptation Challenges and Opportunities for the European Energy System; European Environment Agency: Copenhagen, Denmark, 2019.

4. Pérez-Andreu, V.; Aparicio-Fernández, C.; Martínez-Ibernón, A.; Vivancos, J.L. Impact of climate change on heating and cooling energy demand in a residential building in a Mediterranean climate. Energy 2018, 165, 63-74. [CrossRef]

5. Hueging, H.; Haas, R.; Born, K.; Jacob, D.; Pinto, J.G. Regional Changes in Wind Energy Potential over Europe Using Regional Climate Model Ensemble Projections. J. Appl. Meteorol. Climatol. 2013, 52, $903-917$. [CrossRef]

6. Löffler, K.; Hainsch, K.; Burandt, T.; Oei, P.Y.; Kemfert, C.; von Hirschhausen, C. Designing a Model for the Global Energy System-GENeSYS-MOD: An Application of the Open-Source Energy Modeling System (OSeMOSYS). Energies 2017, 10, 1468. [CrossRef]

7. Pursiheimo, E.; Holttinen, H.; Koljonen, T. Inter-sectoral effects of high renewable energy share in global energy system. Renew. Energy 2019, 136, 1119-1129. [CrossRef]

8. Fattori, F.; Albini, D.; Anglani, N. Proposing an open-source model for unconventional participation to energy planning. Energy Res. Soc. Sci. 2016, 15, 12-33. [CrossRef]

9. Tahir, M.F.; Chen, H.; Javed, M.S.; Jameel, I.; Khan, A.; Adnan, S. Integration of Different Individual Heating Scenarios and Energy Storages into Hybrid Energy System Model of China for 2030. Energies 2019, 12, 2083. [CrossRef]

10. Heinrichs, H.U.; Markewitz, P. Long-term impacts of a coal phase-out in Germany as part of a greenhouse gas mitigation strategy. Appl. Energy 2017, 192, 234-246. [CrossRef]

11. Pfenninger, S.; Pickering, B. Calliope: A multi-scale energy systems modelling framework. J. Open Source Softw. 2018, 3, 825. [CrossRef]

12. Welder, L.; Ryberg, D.; Kotzur, L.; Grube, T.; Robinius, M.; Stolten, D. Spatio-temporal optimization of a future energy system for power-to-hydrogen applications in Germany. Energy 2018, 158, 1130-1149. [CrossRef]

13. Howells, M.; Rogner, H.; Strachan, N.; Heaps, C.; Huntington, H.; Kypreos, S.; Hughes, A.; Silveira, S.; DeCarolis, J.; Bazillian, M.; et al. OSeMOSYS: The Open Source Energy Modeling System. Energy Policy 2011, 39, 5850-5870. [CrossRef]

14. Brown, T.; Hörsch, J.; Schlachtberger, D. PyPSA: Python for Power System Analysis. J. Open Res. Softw. 2018, 6. [CrossRef]

15. Hilpert, S.; Kaldemeyer, C.; Krien, U.; Günther, S.; Wingenbach, C.; Plessmann, G. The Open Energy Modelling Framework (oemof) - A new approach to facilitate open science in energy system modelling. Energy Strategy Rev. 2018, 22, 16-25. [CrossRef]

16. Richstein, J.C. Open Energy Modelling Initiative. 2019. Available online: https://www.openmod-initiative. org (accessed on 17 October 2019).

17. Brown, T.; Schlachtberger, D.; Kies, A.; Schramm, S.; Greiner, M. Synergies of sector coupling and transmission reinforcement in a cost-optimised, highly renewable European energy system. Energy 2018, 160, 720-739. [CrossRef]

18. Gerbaulet, C.; von Hirschhausen, C.; Kemfert, C.; Lorenz, C.; Oei, P.Y. European electricity sector decarbonization under different levels of foresight. Renew. Energy 2019, 141, 973-987. [CrossRef]

19. Schlachtberger, D.; Brown, T.; Schäfer, M.; Schramm, S.; Greiner, M. Cost optimal scenarios of a future highly renewable European electricity system: Exploring the influence of weather data, cost parameters and policy constraints. Energy 2018, 163, 100-114. [CrossRef] 
20. Pfenninger, S.; Pickering, B. Mathematical Formulation of the Calliope Framework. 2019. Available online: https:/ / calliope.readthedocs.io/en/stable/user/ref_formulation.html (accessed on 17 October 2019).

21. ENTSO-E. Indicative Values for Net Transfer Capacities (NTC) in Europe, Summer 2010, Working Day, Peak Hours (Non-Binding Values); European Network of Transmission System Operators (ENTSO-E): Brussels, Belgium, 2010.

22. ENTSO-E. Ten-Year Network Development Plan 2016. Available online: https://www.entsoe.eu/ publications/tyndp/tyndp-2016 (accessed on 17 October 2019).

23. Gotzens, F.; Heinrichs, H.; Hake, J.F.; Allelein, H.J. The influence of continued reductions in renewable energy cost on the European electricity system. Energy Strategy Rev. 2018, 21, 71-81. [CrossRef]

24. Gotzens, F.; Heinrichs, H.; Hörsch, J.; Hofmann, F. Performing energy modelling exercises in a transparent way-The issue of data quality in power plant databases. Energy Strategy Rev. 2019, 23, 1-12. [CrossRef]

25. Staffell, I.; Pfenninger, S. Using bias-corrected reanalysis to simulate current and future wind power output. Energy 2016, 114, 1224-1239. [CrossRef]

26. Pfenninger, S.; Staffell, I. Long-term patterns of European PV output using 30 years of validated hourly reanalysis and satellite data. Energy 2016, 114, 1251-1265. [CrossRef]

27. Intergovernmental Panel on Climate Change (IPCC). Safeguarding the Ozone Layer and the Global Climate System-Issues Related to Hydrofluorocarbons and Pefluorocarbons; IPCC: Cambridge, UK, 2005.

28. Open Power System Data. Data Package Time Series. Available online: https://data.open-power-systemdata.org/time_series/2019-06-05 (accessed on 17 October 2019).

29. Kotzur, L.; Markewitz, P.; Robinius, M.; Stolten, D. Impact of different time series aggregation methods on optimal energy system design. Renew. Energy 2018, 117, 474-487. [CrossRef]

30. ENTSO-E. Statistical Factsheet 2015. 2018. Available online: https://docstore.entsoe.eu/Documents/ Publications/Statistics/Factsheet/entsoe_sfs2015_web.pdf (accessed on 17 October 2019).

(C) 2020 by the authors. Licensee MDPI, Basel, Switzerland. This article is an open access article distributed under the terms and conditions of the Creative Commons Attribution (CC BY) license (http:/ / creativecommons.org/licenses/by/4.0/). 